\title{
An Experimental Study of Bond Market Pricing*
}

\author{
Matthias Weber ${ }^{\dagger} \quad$ John Duffy Arthur Schram $^{\S}$
}

August 2, 2016

\begin{abstract}
An important feature of bond markets is the relationship between initial public offering prices and the probability of the issuer defaulting. First, this probability affects the bond prices. Second, IPO prices determine the default probability. Though market equilibrium has been shown to predict well for other assets, it is a priori unclear whether markets will yield competitive prices when such interaction with the default probability occurs. We develop a flexible bond market model that is easily implemented in the laboratory and examine how subjects price bonds. We find that subjects learn to price bonds well after only a few repetitions.
\end{abstract}

JEL classification: C92, C90, D47, G12

Keywords: bond markets, experimental finance, experimental markets, asset pricing, learning

*Financial support by The Netherlands' Organization for Scientific Research (NWO grant 406-11022) and the Research Priority Area Behavioral Economics of the University of Amsterdam is gratefully acknowledged. Thanks for comments and suggestions go to Frédéric Schneider, participants of the Experimental Finance Conference in Mannheim, and seminar participants in Amsterdam and Vilnius. Disclaimer: The views expressed are those of the authors and do not necessarily reflect those of the Bank of Lithuania or the Eurosystem.

${ }^{\dagger}$ CEFER, Bank of Lithuania \& Faculty of Economics, Vilnius University. Part of the work on this paper was conducted while Weber was at the University of Amsterdam (CREED). Email: mweber@lb.lt.

†University of California, Irvine. Email: duffy@uci.edu

${ }^{\S}$ Robert Schumann Center for Advanced Studies, EUI (Florence) and University of Amsterdam. Email: arthur.schram@eui.eu 


\section{Introduction}

Many firms and governments raise funds by issuing debt through the sale of bonds. Indeed, bond markets dwarf markets for other assets such as equities in terms of the value of outstanding issues. The reason is that bond sales are often the cheapest means of financing as compared with alternatives, e.g., equity issues or bank loans, and indeed, bond issues comprise the primary means of financing for most large, mature firms and governments. This preference for bond financing, however, presumes that bond purchasers are able to correctly price new bond issues. If newly issued bonds are mispriced relative to fundamentals, the financing costs to the bond issuer may be increased, leading to an increase in the issuer's default risk. In turn, this risk of default affects the bond's fundamental price.

In this paper we explore the extent to which an initial public offering (IPO) of bonds by a bond issuer is correctly priced by investors who must take into account this twoway interdependency between IPO prices and default risk. Specifically, we develop and evaluate the empirical relevance of a model of bond pricing based on Merton (1974), which relates IPO prices to features of the bond issue (e.g., face value, coupon payment, maturity date) and the probability that the bond issuer defaults on its obligations to bond holders. Rather than use field data, we pursue an experimental approach where subjects in a laboratory are asked to buy new bond issues and earn money proportionate to the bond market setting in which they operate. The main advantage of a laboratory evaluation of bond market pricing is that we have control over the information that is available to bond purchasers regarding features of the bond issuance and in particular the probability that the bond issuer defaults, and we can evaluate the extent to which they use this information to determine bond prices. Knowledge of such information and this same level of control are not generally available or feasible in the field. For this reason there is now a large literature using experimental methods to evaluate the pricing of many types of assets (see, e.g., Bossaerts, 2009, for a survey).

This experimental asset pricing literature has primarily focused on assets that are not subject to default. While bond market pricing is similar in many respects to the pricing of other types of assets, e.g., equities, the interdependence of prices in the initial public offering (IPO) of bonds and the probability of the bond issuer defaulting makes bond markets structurally different from all other asset markets. To our knowledge, there is no prior experimental evaluation of bond market pricing that explores whether investors are able to comprehend these interdependencies. For this reason, it remains unclear whether the knowledge accumulated in a rich literature on experimental asset 
markets carries over to the case of bond markets. ${ }^{1}$ Given the great importance of bond markets as a means of financing, an experimental evaluation of bond pricing seems warranted. Our study fills this gap in the literature.

To preview our results, we find that subjects learn to price bonds rather well after only a few repetitions (both during the IPO and while trading in the secondary market afterward). As in other asset pricing experiments, we find that bubbles in bond prices are only observed among inexperienced traders. This is remarkable, given that the bonds in our experiments are relatively long lived, giving ample opportunity for bubbles to occur (e.g., Noussair and Tucker, 2013). The overall high degree of market efficiency that we find occurs in environments with both increasing and decreasing (equilibrium) fundamental values for bonds.

The remainder of this paper is organized as follows. In the following section we situate our paper in the experimental asset pricing literature. Section 3 describes the model of bond market pricing that will be used in our experiment. Section 4 presents the experimental design and the results are discussed in Section 5. Section 6 concludes.

\section{Literature}

While there is now a large literature on experimental asset pricing, ${ }^{2}$ there are few studies examining the pricing of assets with the particular properties of bonds. Indeed, recent surveys of the experimental asset pricing literature by Bossaerts (2009), Noussair and Tucker (2013), and Palan (2013) reveal just a few experiments that explicitly consider assets labeled as "bonds"; more generally assets are simply labeled as "assets". In the studies that do refer to certain assets as bonds, the bonds are included primarily as a means of expanding the portfolio of assets available to traders. For instance, Bossaerts et al. (2010b) allow agents to trade in riskless bonds paying a known fixed return by contrast with other assets having either known probabilistic (risky) returns or ambiguous returns in their study of risk versus ambiguity aversion. Fischbacher et al. (2013) allow agents to trade in a riskless, interest-bearing bond as well as a Smith et al. (1988)-type risky asset. The latter is known to exhibit price bubbles and crashes and so

\footnotetext{
${ }^{1}$ The experimental literature on simple asset markets has provided a large number of studies with various robust findings. In particular, prices in the final periods of a multi-period market tend to converge to fundamental values after a few replications of the market. However, sustained deviations from the fundamental price (e.g., bubbles) are regularly observed in markets that cover many periods.

${ }^{2}$ For some of the more recent studies, see Gneezy et al. (2003), Dufwenberg et al. (2005), Haruvy and Noussair (2006), Bossaerts et al. (2007), Haruvy et al. (2007), Bossaerts et al. (2010a), Palan (2010), Cheung and Palan (2012), Kirchler et al. (2012), Sutter et al. (2012), Cheung et al. (2014), Füllbrunn et al. (2014b), Bosch-Rosa et al. (2015), and Crockett and Duffy (2015).
} 
the authors' aim is to explore the role of interest rate (monetary) policy (via the riskless bond) on the extent of mispricing of the risky asset. By contrast, our focus in this paper is on bond pricing alone, with a particular focus on the initial price of bonds. ${ }^{3}$ Further, we are not interested in risk-free bonds, but rather in bonds that are subject to default risk. Most corporate bonds and some government bonds are subject to this type of risk. We are not aware of any prior experimental studies examining the pricing and trading of bonds subject to default risk.

The frequency of real-world bond defaults, based on the historical record, tends to be lower than the probability implied by the initial prices of bonds subject to default risk (see, e.g., Hull et al., 2005). Indeed, the credit spread between risk-free government securities and comparable corporate bonds subject to default risk is many times greater than can be explained by the risk of default alone, a phenomenon known in the literature as the "credit spread puzzle" (Amato and Remolona, 2003). The reasons for the mispricing of bonds subject to default risk are unclear, but several explanations have been offered that depart from the standard theory, including: 1) difficulties estimating the bond issuer's default risk, 2) demand for a risk premium, representing a departure from the assumption of risk neutral traders, and 3) systematic macroeconomic factors that can affect the default risk of all bond issuers simultaneously but which cannot be diversified away. The main advantage of our laboratory approach is that it allows us to abstract from these potentially confounding factors and therefore to provide a cleaner test of the theory of bond pricing subject to default risk. In particular, we make clear to subjects the function mapping IPO prices into default probabilities. Further, aside from the possibility of a default, there are no other shocks to the environment in which subjects make decisions. Our main finding is that subjects eventually do learn the difficult task of pricing bonds subject to default risk given knowledge only of the mapping between the IPO price and default risk. This finding suggests that the source of the credit spread puzzle may indeed lie with factors or assumptions that are not presently found in the theory of bond pricing subject to default risk.

\footnotetext{
${ }^{3}$ Regarding initial public offer mechanisms, Zhang (2009) experimentally compares uniform price auctions (which we use in our experiment) versus fixed price offerings of initial equity shares. He reports greater revenues under the uniform price auction mechanism, despite the possibility of collusion under that mechanism. Füllbrunn et al. (2014a) investigate different IPO mechanisms in the laboratory. They find underpricing under all mechanisms considered.
} 


\section{Bond Market Model}

In this section, we introduce a model of bonds subject to default risk that captures the essential features of the theory (see, e.g. Merton (1974)) but which is tractable enough to be implemented in the laboratory. We first give a brief overview of the model. Then we discuss the timing of moves and derive the fundamental value of the bond given a default probability. Finally, we discuss how the IPO price and the default probability are connected.

\subsection{Brief Description}

The payments to a bond holder are as follows. If the bond issuer does not default prior to the bond's maturity date in period $T$, then the bond holder receives a payment of the face value $K$. Prior to the maturity date for the bond, the bond holder also receives a coupon payment of $i K$ in each period ( $i$ is thus the interest rate) so long as the bond issuer has not defaulted. If the bond issuer defaults at some point, the bond holder receives no more coupon payments from the period of default onward and also loses payment of the bond's face value. ${ }^{4}$

When the bond issuer issues bonds, they are auctioned off in an IPO. The importance of this IPO to the bond issuer's financing costs is the biggest difference between a bond market and other asset markets. The prices paid in the bond market IPO determine the costs to the bond issuer of its fixed maturity debt issue (the lower the IPO price, the higher are the costs of the debt). These costs have an influence on how likely it is that a bond issuer will default over the fixed term of the bond (the higher the costs, the higher is the probability that the bond issuer defaults). ${ }^{5}$

We use a single- (or uniform-) price call market auction for the IPO, as it facilitates the specification of the probability that the bond issuer will default. In this auction, the face value and the coupon payments are fixed and known and the potential bond

\footnotetext{
${ }^{4}$ More generally, one can specify a default amount, $D$, which the bond holder receives in the event that the bond issuer defaults (cf., Merton, 1974). In the following we always assume that there is no such payment (i.e., $D=0$ ) for simplicity. Similarly, one could add an outside interest rate for holding money $r$, which we also assume to be zero for simplicity in the remainder of the paper.

${ }^{5} \mathrm{By}$ contrast, IPO prices for other assets such as equities, which have no fixed maturity date, have a less direct effect on the financial health of the issuer as equities only promise a share of the issuer's profits and do not commit the issuer to a certain debt repayment amount. A second difference between bonds and equities is that bonds pay both a fixed, period-by-period interest (coupon) payment as well as having a fixed terminal (face) value, while equities typically pay (at most) only a dividend in each period. Most previous asset-market experiments follow this distinction, paying a random dividend amount in each period and no terminal value.
} 
holders bid on the price they are willing to pay to receive a bond. ${ }^{6}$ Once all bonds have been auctioned off, they can be regularly traded on a secondary market where prices are determined by supply and demand. For this purpose we again use a call market, this time a two-sided version, where subjects can act as both buyers and sellers. Trade takes place over several periods, up to the maturity date period $T$, assuming of course that there is no default prior to that date.

\subsection{Timing and Fundamental Value with Known Default Probabili- ties}

The price in the IPO determines the default probability of the bond issuer. After the IPO, the default probability of the bond issuer remains constant until either default occurs or period $T$, is reached. ${ }^{7}$ Once the default probability is known, the fundamental value of the bonds in all subsequent periods can be calculated. The calculation of these fundamental values depends on the timing of the market, which we now discuss.

In the initial period 0 , the IPO of bonds is held. The result is a market clearing price, which we refer to as the IPO price, $p_{i p o}$. Thereafter, in periods $t=1,2, \cdots T-1$ bond market participants can buy and sell bonds provided that they have bonds to sell or funds to buy bonds. Specifically, the timing of moves in each of periods $0<t<T$ is as follows:

1. It is determined whether or not the bond issuer defaults.

2. Conditional on no default having occurred in the current period or earlier, the coupon payment is made.

3. The bond market opens and trade in bonds can take place.

Finally, if the final period $T$ is reached, (i.e., no default has occurred in period $T$ or earlier) then (i) no more trading occurs and (ii) the face value of the bond is paid out together with the final coupon payment.

\footnotetext{
${ }^{6}$ It is of course possible to use alternative auction mechanisms and indeed, different mechanisms are used in real-world bond IPOs. If an auction does not allocate the bonds at a uniform price, then the specification of the default probability is slightly more complicated. Instead of holding face value and coupon payments constant, one can also hold face value and initial price constant and allocate the bonds in an auction where bids are made on the coupon payments. We choose to use the version where coupon payments are fixed, because this leads to a large similarity between the initial auction and the trading in the secondary market in the experiment.

${ }^{7}$ We assume for simplicity that the default probability is constant in all periods, but one could relax this assumption. We also assume that a subsequent IPO can only take place after the bonds from the previous IPO have been redeemed. One could also model overlapping 'generations' of bonds; however, this would make modeling the default probability more complex, because it would then depend on a combination of IPO prices of all bonds in the market.
} 
The default probability depends on the IPO price; the precise way in which IPO prices map into default probabilities is described later in Section 3.3. Once the default probability, $P_{d}$, is known (the probability of not defaulting is $P_{n}:=1-P_{d}$ ), the fundamental price of a bond in period $t$ can be calculated. Note that the fundamental value, $V_{t}$, of the bond in period $t$ is conditional on the bond holder not having previously defaulted. The fundamental value of a bond is then the face value times the probability of receiving this final payment plus the expected value of the remaining coupon payments:

$$
\begin{gathered}
V_{t}=K P_{n}^{T-t}+\sum_{m=t+1}^{T} i K P_{n}^{(m-t)}=K P_{n}^{T-t}+\sum_{m=1}^{T-t} i K P_{n}^{m} \\
\stackrel{\text { for }}{\stackrel{P_{d}}{=}}{ }^{>0} K P_{n}^{T-t}+i K\left(\frac{1-P_{n}^{T-t+1}}{1-P_{n}}-1\right) .
\end{gathered}
$$

\subsection{Default Probability and Equilibrium Fundamental Value}

The default probability of a bond depends on the bond's IPO price and is thus endogenously determined. As a higher IPO price leads to lower financing costs for the bond issuer and therefore a lower probability of default, the function mapping IPO prices into default probabilities is assumed to be monotonically decreasing. We model the default probability using an exponential function:

$$
P_{d}\left(p_{i p o}\right)=m \exp \left(-c p_{i p o}\right)+b
$$

The parameter $b$ (with $0<b<1$ ) represents a base risk (the default probability can never be lower than $b$ ). The parameter $m$ (with $0<m<1-b$ ) represents the maximal bond-price dependent default probability. Thus, this is the maximal possible probability of default due to low bond prices. The highest possible default probability is then $m+b$ (which may be smaller than 1 even if a bond issuer receives a price close to zero for its bonds; this is because the bond issuer might have other means of debt financing such as equity issue or taxes - and may choose not to default in order to reestablish credibility). The parameter $c$ (with $c>0$ ) determines the sensitivity of the default probability to variations in the IPO price (the smaller is $c$, the less sensitive is the default probability to the IPO price, i.e., the flatter is the default probability function). As the probability of default is now endogenous, one cannot simply calculate the fundamental value of the bond in the IPO. However, it is possible to calculate equilibrium prices for the IPO and use these to determine the equilibrium fundamental values with (1). Of course, the actual fundamental value after period 0 depends on the realized IPO-price. The equilibrium fundamental values do not have an easy closed-form 
solution but can be easily obtained numerically. ${ }^{8}$

The model is very flexible. By varying either coupon payments, the face value of the bond or the default probability function, different paths of (equilibrium) fundamental values can be achieved. This flexibility is important as the slope of an asset's fundamental value over time plays an important role in the experimental asset market literature (see Noussair et al., 2001, Kirchler, 2009, Noussair and Powell, 2010, Huber and Kirchler, 2012, Kirchler et al., 2012, Breaban and Noussair, 2014, Giusti et al., 2014, and Stöckl et al., 2014). ${ }^{9}$

\section{Experimental Design and Procedures}

The experiment was programmed in PHP/MySQL and conducted in English at the CREED laboratory of the University of Amsterdam with a total of 96 subjects recruited from the CREED subject pool (eight groups of six subjects in each of two treatments). After each session, participants had to fill out a short questionnaire. Participants were primarily undergraduate students, the average age was about 23 years. About half of the participants were female, about two thirds were majoring in economics or business, and about 60 percent were Dutch. During the experiment, 'points' were used as currency. These points were exchanged into euros at the end of each session at a known exchange rate of 1 euro per 1000 points. The experiment lasted about two and a half hours. Participants earned on average 27.55 euros (including a show-up fee of 7 euros). The experimental instructions are reproduced in Appendix A. After reading the instructions and prior to the start of the experiment, subjects had to correctly answer a set of comprehension test questions. These test questions are reproduced in Appendix B.

\subsection{Treatments}

The experiment consists of two treatments. In one, which we call $D E C$, the equilibrium fundamental value of a bond is decreasing over time while in the other, $I N C$, the

\footnotetext{
${ }^{8}$ For any IPO price the expected return to investing in a bond is the fundamental value minus the price. With risk-neutral investors, equilibrium IPO-prices are those that yield zero expected returns; with positive returns investors would have an incentive to bid more, driving up prices and driving down returns.

${ }^{9}$ Furthermore, the model specifications can be chosen such that more than one equilibrium price arises, for example a high-price equilibrium with a low probability of default and a low price equilibrium with a high probability of default. Because this is the first paper on experimental bond markets, our focus is on the extent to which equilibrium is reached and not on equilibrium selection. We therefore leave this possibility unexplored, by choosing a specification that yields a single (unique) equilibrium.
} 
equilibrium fundamental value of a bond is increasing over time (for references on the importance of the slope of fundamental values in asset market experiments see the end of the previous section). The difference in the equilibrium paths is realized by using distinct parameterizations of the probability of default function. Our choice of parameters was guided by the following considerations. ${ }^{10}$ Most importantly, a parameterization was chosen that equalizes the equilibrium fundamental value at the IPO in both treatments. Because subjects also received the same endowment in both treatments, both treatments have the same cash to asset ratio in the IPO and also the same ratio of cash to the value of assets priced at the equilibrium price. In equilibrium, subjects receive zero expected earnings. A monetary incentive for subjects to buy and trade only exists when prices are below the (equilibrium) fundamental price. One can determine the IPO price for which the expected earnings (and, therefore, the incentive to participate in the market) are maximized. Note that this 'maximal-earnings' price is generally not zero, because a zero price will lead to a very high probability of default. In the experiment, we ensure that the maximal expected earnings in the two treatments are of equal magnitude. ${ }^{11}$ Obviously, if equilibrium prices in the IPO are equal between treatments while (equilibrium) fundamental values are increasing in one case and decreasing in the other, then face values must be different. The requirements to keep equilibrium IPO prices and maximal expected earnings equal across treatments, together with the wish to avoid parameterizations that yield multiple equilibria make it necessary to introduce several differences in the parameters.

Specifically, the parameterizations chosen in the two treatments are as follows. In $D E C$ the parameters of the probability default function are $b=0.02, m=0.6$, and $c=0.003$. In $I N C$ these are $b=0.14, m=0.25$, and $c=0.00175$. The interest rate is the same in both treatments, $i=0.12$. The face value of bonds is $K=1000$ points in $D E C$ and $K=2500$ points in $I N C$. Graphs of the two probability default functions used in the experiment are shown in Figure 1. The treatment variation generating decreasing or increasing equilibrium fundamental values is realized via these probability default functions (and the bond's face value).

Using different probability default functions to achieve different treatments reflects the greater intricacies of bonds markets relative to other asset markets. Treatment DEC uses a default probability function that is decreasing fast in the IPO price from a very high level to a very low level. Treatment INC uses a default probability function with

\footnotetext{
${ }^{10}$ There are some minor differences between the two treatments due to our preference for round numbers. It is not reasonable to expect that these minor differences have a noticeable impact on the outcomes.

${ }^{11}$ This does not mean that the IPO price at which the maximum is achieved is the same in both treatments, because the probability default functions are different.
} 


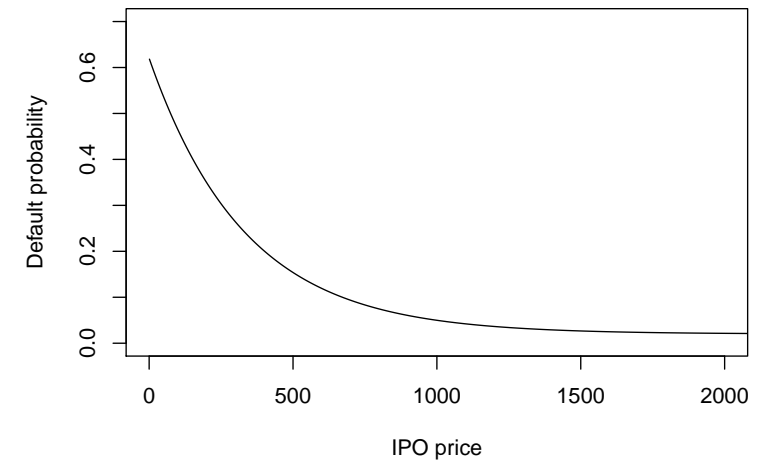

(a) Treatment $D E C$

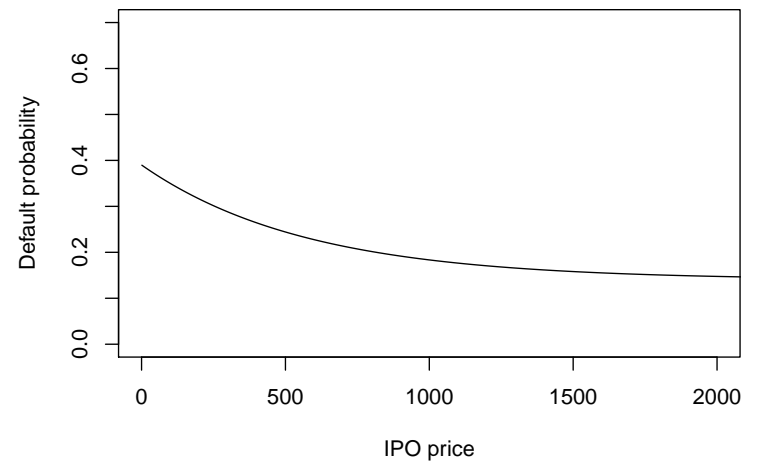

(b) Treatment INC

Figure 1: Default Probability Functions in both Treatments

Notes: The graph shows the default probability as a function of IPO prices in both treatments.

a lower maximal default probability than in $D E C$, but the function decreases more slowly in the IPO price. In equilibrium, the IPO price is approximately 1860 points in both treatments and the equilibrium default probability is higher in $I N C$ than in $D E C .^{12}$ The bonds in $D E C$ can be thought of as bonds from an issuer with a large outstanding debt who is otherwise economically strong - in equilibrium the probability of default is quite low. However if the financing costs were to increase sharply, a default would become much more likely. The bonds in $I N C$ can be thought of as bonds from an issuer facing economic troubles (which could be an economy in a severe recession or a firm with an uncertain future) with rather small outstanding debt - the probability of default is high, but the relatively low level of outstanding debts mitigates the negative reaction to increases in financing costs.

The different default probability functions lead to distinct (equilibrium) paths for the fundamental value. These paths are shown in Figure 2 for both treatments with solid lines. The equilibrium value for the IPO is shown as the period 0 value in the graph.

Aside from the (equilibrium) fundamental values, the graphs in Figure 2 show a second price. This is the price that maximizes (expected) joint earnings across subjects. Because bonds are only allocated once (at the IPO), the joint earnings themselves do not change after the IPO. In traditional experimental asset markets, joint earnings are maximized by initially buying the assets (from the experimenter) at the lowest allowable price. In a bond market, such minimal prices typically do not maximize joint earnings because of the effect that the IPO price has on the probability of default. The joint earnings maximizing price in the IPO is shown by the value of the dashed line at period

\footnotetext{
${ }^{12}$ More precisely, the equilibrium IPO price is 1860.9 in DEC and 1862.4 in INC.
} 


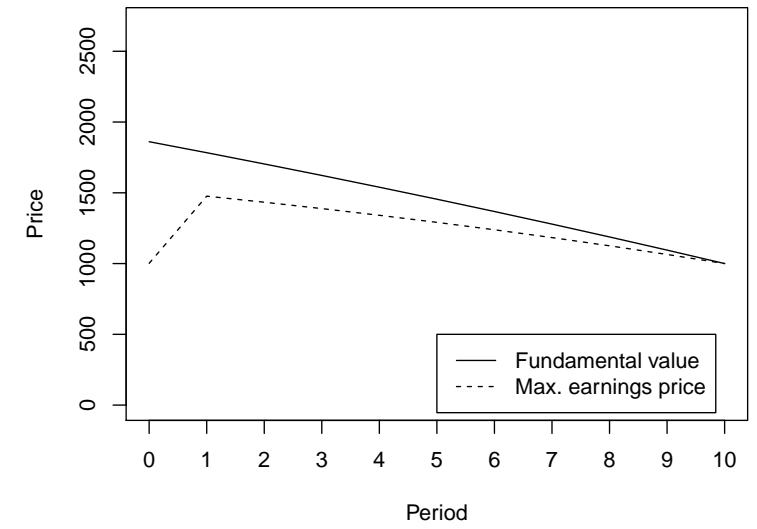

(a) Treatment $D E C$

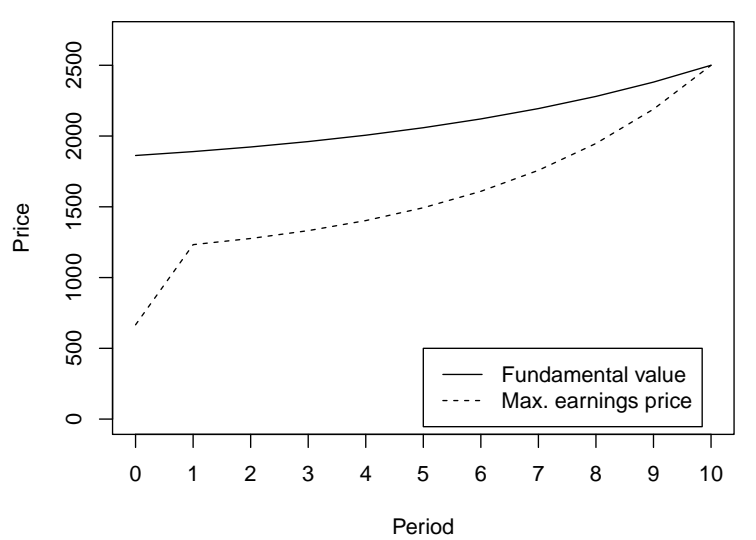

(b) Treatment INC

Figure 2: Fundamental Values in both Treatments

Notes: The graph shows the equilibrium fundamental values in both treatments (solid lines). It also shows the price that yields the highest expected joint earnings for the subjects (dotted line).

0. If bidders could collude against the issuer (i.e., the experimenter) they would in theory coordinate on this IPO price. This price is always below the equilibrium price and does not depend on the number of subjects per group. After the initial allocation in the IPO, the aggregate number of bonds in the market remains constant and collusion can no longer affect joint earnings. Subsequently, the dashed line from periods 1 to 10 represents the fundamental value of the bond conditional on the joint earnings maximizing IPO price having been realized. This explains the kink in the curve after moving from the IPO period 0 to the first regular trading period 1 . As the default probability depends on the IPO price, the continuation of this line after period 1 is not identical to the equilibrium fundamental value line (the solid line), though by the final period $T$, the two values become equal.

\subsection{Experimental Timing}

At the beginning of the experiment, subjects are randomized into groups (i.e. markets) of size six. Group membership remains the same over the course of the experiment and subjects can only interact with the five other members of their own group when buying/selling bonds in the IPO and when trading in the market in subsequent periods. The IPO auction and the trading mechanism are as described in Section 4.3.

In the experiment there are four identical rounds. Each round consists of 11 periods, numbered from 0 (the IPO) to 10. At the end of the experiment, for each subject one of the rounds is randomly selected for payment. Subjects start each round with an 
endowment of 20,000 points. The initial endowment is booked on a 'cash account' which is used for all transactions subjects make when buying or selling bonds. The number of bonds allocated in the IPO is 25 per group. After the initial auction in period 0 , subjects can trade the bonds with one another in periods 1 to 9 (henceforth, the 'trading periods'; in period 10 no more trade takes place). The proceeds subjects receive from the coupon payments are deposited into an account called the interest account'. The money on this interest account cannot be used to buy bonds; this is to ensure that the stock of cash in the economy remains constant in the trading periods.

In order to collect data on all periods, even after a default has occurred, we use a block design (see e.g. Fréchette and Yuksel, 2013). In this design, subjects are not told immediately whether a default has occurred. Instead, all markets continue for 9 trading periods as if no default has occurred. Only at the end of the round (i.e., following period 10) are subjects told whether a default had occurred and, if so, in which period. In case that a default had occurred, subjects' final earnings for a round are determined according to their cash and interest account balances in the period of default. This means that any action a subject takes is only payoff relevant conditional on no default having yet occurred in the round. This procedure is described carefully in the experimental instructions (see Appendix A). Figure 3 shows a schematic overview of the timeline of the experiment.

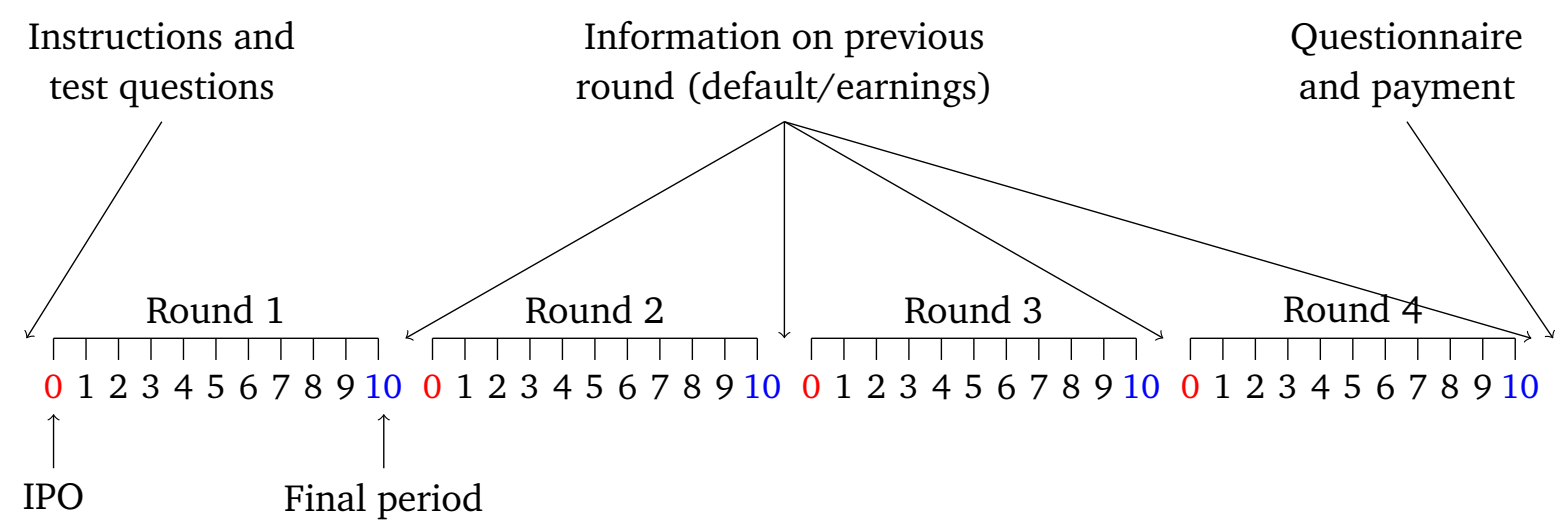

Figure 3: Timeline of the Experiment

Notes: The four rounds are identical. For each participant the earnings of one of the rounds are randomly selected for payment. Period 0 is the IPO, period 10 is the final period of a round in which no more trading takes place. 


\subsection{Trading Mechanisms}

The one-sided call market mechanism used for the IPO in period 0 is implemented as follows. Each subject submits a demand schedule, i.e., specifies for chosen prices how many bonds they would like to buy at each of those prices. Then, the computer program constructs an aggregate demand schedule by sorting bids from highest to lowest. The intersection of this demand schedule with the fixed supply of 25 bonds determines the uniform IPO price at which the bonds are sold. Note that this amounts to the highest price for which all 25 bonds can be sold. If there are multiple bids at this market clearing price, then the successful bids are randomly determined, that is, some buyers are rationed.

The trading mechanism used in periods 1 to 9 is also a call market, but now a doublesided one. Subjects submit individual supply and demand curves. The computer program returns a warning if bids are invalid (for example if a subject tries to bid for a combination of bonds that she cannot afford with the points she has available in her account). Then the program constructs demand and supply curves by sorting bids from highest to lowest and asks from lowest to highest. The market-clearing price is determined by the intersection of these aggregate supply and demand curves, and all trade is carried out using this uniform market price. If there is a vertical overlap of the demand and supply curves (i.e., if there is an interval of prices at which the maximal number of trades can be carried out), then the midpoint of this interval is taken as market price. If there is excess demand or supply at the market price, then successful bids or offers are randomly determined.

Figure 4 shows the interface where subjects enter their demand function for the IPO of period 0. To start, one empty row is available to enter a quantity and a price, but subjects can add as many rows as needed by clicking on a button 'show more fields'. In the trading periods 1-9, that follow the IPO, subjects see similar input fields on the same screen where they can also enter their supply schedule. These input fields for supply choices are placed to the right of the input fields for demand choices. An important advantage of the two mechanisms used for the IPO and trading periods lies in their similarity. De facto, subjects only need to become familiar with one mechanism and interface. In addition to the input fields, subjects see one button on the screen to submit bids in the IPO or to submit bids and offers simultaneously in the trading periods. Subjects also see past market prices in the round concerned. If no trade occurred in a previous period, this is indicated instead of the market price. 
I would like to buy this quantity

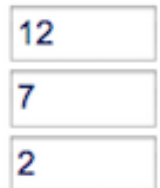

if the price (per asset) is at most

356

688

911.5

show more fields

Figure 4: Input Fields of the Computer Interface to Submit a Demand Function

\section{Results}

We have data from eight independent groups of six subjects for each of our two treatments. Thus we are reporting results for a total of 96 subjects. Each group participates in four markets, for a total of 32 markets per treatment. The different groups do not interact with one another in any way, so that the 16 observations at the group level can be treated as being statistically independent.

\subsection{Aggregate Observations}

We begin with a brief analysis of aggregate findings. The graphs of all market prices in all rounds and periods for all groups separately can be found in Appendix C. The graphs showing the quantities traded in each group for all rounds and periods can be found in Appendix D.

Figure 5 shows a few examples of paths for observed bond prices. Market prices are shown as (red) circles. When there is no trade, but when both bids and offers are present we indicate the midpoint between highest bid and lowest offer price with a (red) cross. The equilibrium fundamental value is shown as a solid line and the maximum joint earnings line is shown as a dashed line (cf. Figure 2). The actual fundamental value resulting from the IPO-price (i.e., the price in period 0) is shown as a (blue) dotted line. ${ }^{13}$ The figure shows two markets starting out a bit below the equilibrium fundamental value where bonds were priced close to fundamentals in all subsequent

\footnotetext{
${ }^{13}$ The fundamental values may seem quite flat in this graph. This is because the scale of the $y$-axis was chosen to show the highest traded prices. Equilibrium fundamental values decrease from the predicted IPO price of about 1860 in the first period to 1000 (the face value) in the tenth period of $D E C$ and increase from about 1860 in the first period to 2500 (the face value) in the tenth period of INC.
} 
periods, one in DEC and one in INC (Figures 5a and 5c). The figure also shows two markets with pronounced bubbles in the bond price, one in $D E C$ and one in INC. In one case, the bubble is deflated slowly (Figure $5 \mathrm{~b}$ ) while in the other case the bubble bursts with hardly any subsequent trade (Figure $5 \mathrm{~d}$ ).

Bubbles in bond prices are relatively rare. ${ }^{14}$ Most groups learn to price bonds relatively well after the IPO. More precisely, we observe bubbles in four out of the 32 markets in $D E C$ and in five out of the 32 markets in $I N C$. The four bubbles in $D E C$ arise in the first round of one group and in the first three rounds of another group (groups 4 and 7 , respectively, in Figures 14 and 15 in Appendix C). The bubbles in INC arise in the first two rounds of two groups and in the second round of one group (two bubbles in groups 5 and 7 and one bubble in group 6 in Figure 17 in Appendix C). We never observe any bubbles in the last (fourth) round. There is also evidence that subjects learn, over time, to better price the bond in the more complicated environment of the IPO where the default probability is determined, as shown in the next section. Overall, the differences between our two treatments are rather small; learning of prices seems to take place similarly, independent of whether the fundamental value is decreasing or increasing.

Concerning traded quantities, in the IPO, all 25 bonds are always sold. In the trading periods that follow, there is sustained trade in most groups with an average number of trades of around two bonds per period.

We next turn to the main experimental findings, which concern prices in the IPO and in the trading periods. This is followed by a discussion of the incidence of defaults and traded quantities over time.

\subsection{Prices in the IPO}

The IPO (and its importance for the default probability) is the crucial difference between experimental bond markets and other experimental asset markets. It is much more difficult to price the bonds correctly in the IPO than in the trading periods, where the default probabilities have been determined by the IPO price. Therefore, it is an important question whether subjects are able to price bonds well in the IPO and how repeated experience with the IPO influences the initial pricing of the bond issue. Figure 6 shows the IPO prices in both treatments for all groups separately over the four rounds. Table 1 shows the mean prices across groups (represented by the (red) bold line in the graph).

\footnotetext{
${ }^{14}$ There is no generally accepted definition of a bubble. We consider a market to exhibit a bubble if the relative absolute deviation (see Stöckl et al., 2010) is larger than 0.5; this measure of mispricing is described in more detail in Section 5.3.
} 


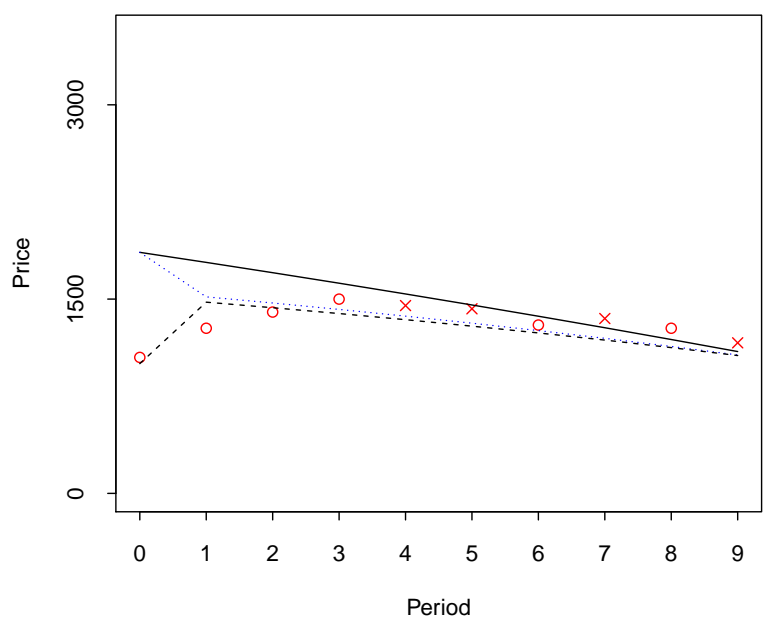

(a) DEC, Group 3, Round 2

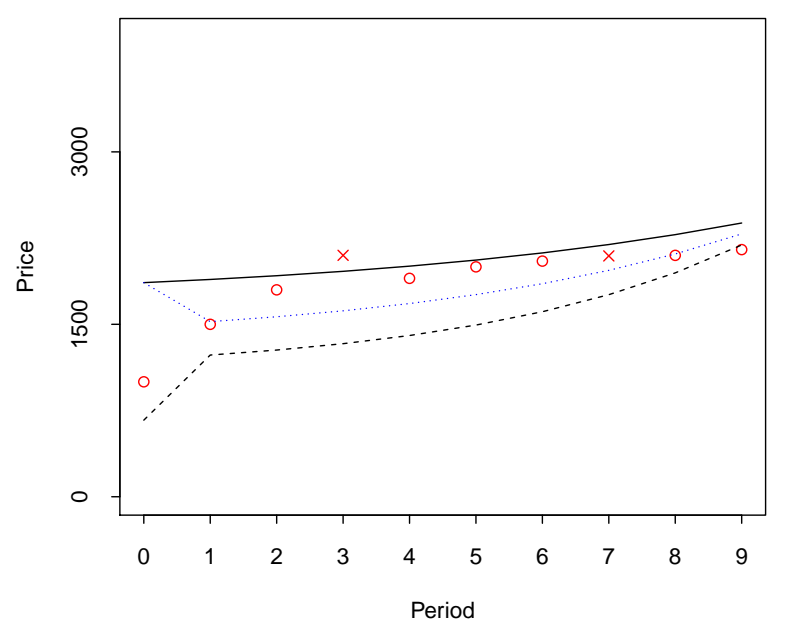

(c) INC, Group 8, Round 1

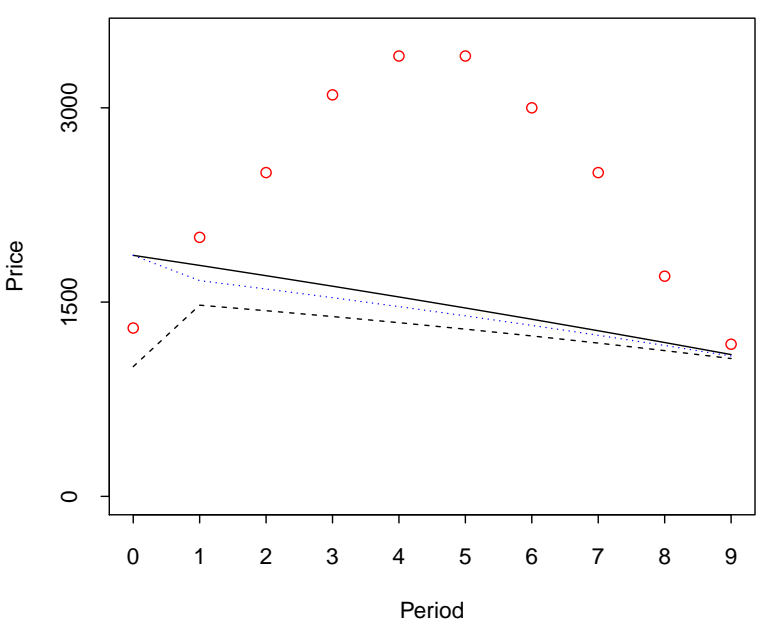

(b) $D E C$, Group 4, Round 1

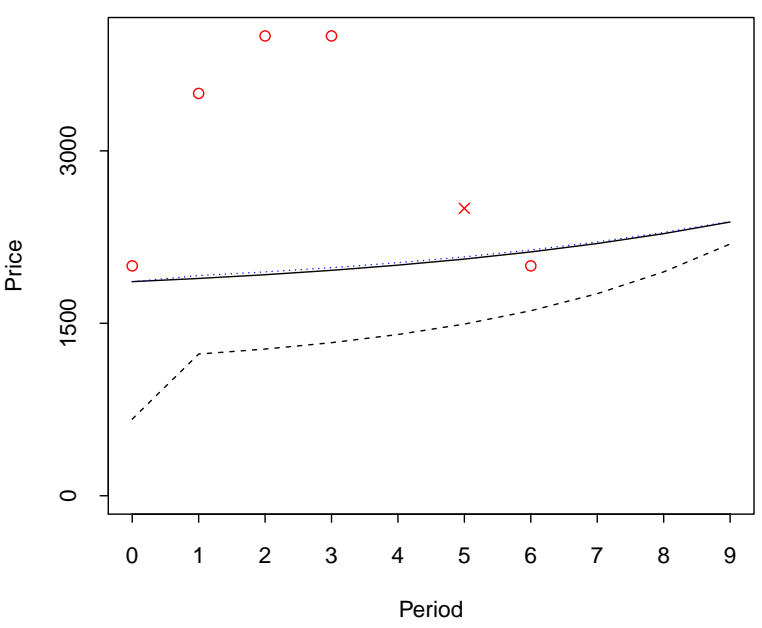

(d) INC, Group 7, Round 2

Figure 5: Examples of Market Prices in the Experiment

Notes: Market prices are shown as red circles. Red crosses show the mean of the highest bid and the lowest offer price when no trade is carried out but when bids and offers are present. The equilibrium fundamental value is shown as a solid black line and the price that maximizes expected joint earnings is given by the dashed black line. The actual fundamental value within a round (which depends on the price in the IPO) is drawn with a dotted blue line. As there is no trade in the tenth period, periods only reach from 0 (the IPO) to period 9. 


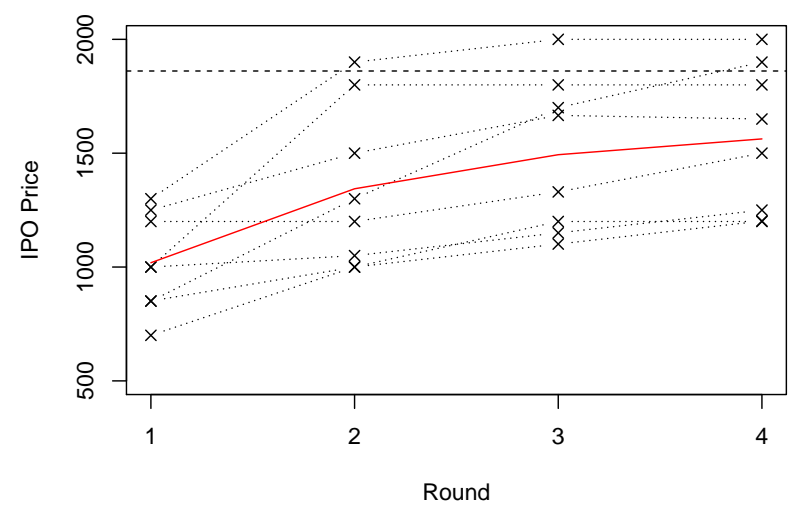

(a) Treatment $D E C$

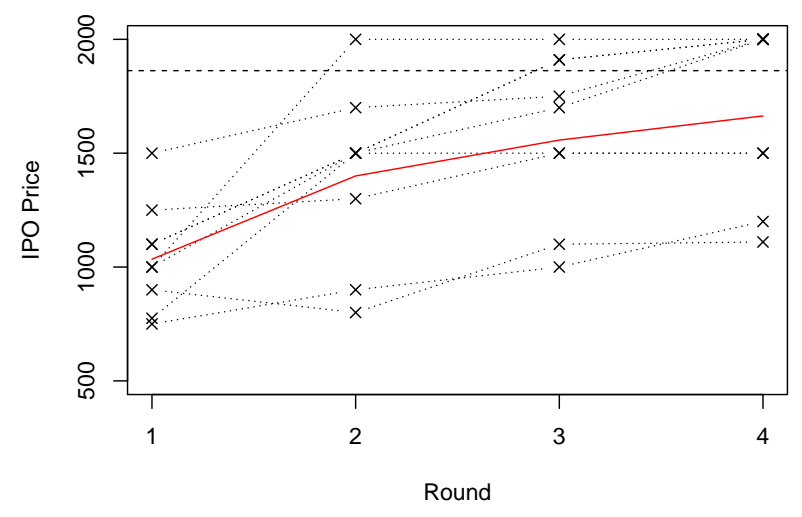

(b) Treatment $I N C$

Figure 6: IPO Prices in all Rounds in both Treatments

Notes: Each cross represents the IPO price of one group in one round. The prices of each group across rounds are connected by a dotted line. The dashed horizontal line is the equilibrium fundamental value in the IPO. The solid red line depicts the average of the eight IPO prices per round (cf. Table 1).

Table 1: Mean IPO Prices

\begin{tabular}{lcccc}
\hline & Round 1 & Round 2 & Round 3 & Round 4 \\
\hline$D E C$ & 1018.88 & 1343.75 & 1493.38 & 1562.75 \\
$I N C$ & 1034.38 & 1400.00 & 1557.50 & 1663.75 \\
\hline
\end{tabular}

Figure 6 shows learning across rounds. Subjects clearly price the bonds better in the final IPO of round 4 than in the first round. This effect is statistically significant. The absolute difference between actual IPO prices and their equilibrium value is smaller in the fourth round than in the first round for both treatments ( $p$-values are below 0.01 in each treatment when tested with a two-sided Wilcoxon rank-sum test).

Pricing the bonds in the IPO is a complicated task as the default probability changes with the IPO price. Nevertheless, subjects price bonds so well that by the fourth round, market prices are distributed around the equilibrium fundamental value, with mean prices somewhat below this value. Recall that the equilibrium fundamental value is derived assuming risk neutral investors; prices somewhat below this value might therefore indicate risk aversion. We check whether the deviation from the equilibrium fundamental value is significant. In the first round, there is a significant difference in both treatments with $p$-values from a two-sided Wilcoxon signed-rank tests of 0.014 in both cases. In the fourth round, IPO prices are still marginally significantly different from 
the equilibrium value in $D E C$ ( $p$-value 0.055 ) but not so in INC ( $p$-value 0.287 ). ${ }^{15}$ It seems that whether the fundamental value in the trading periods is decreasing or increasing plays no particularly important role for how well subjects can price the bonds in the IPO; in line with this observation, IPO prices are not significantly different between treatments for any round ( $p$-values of two-sided Wilcoxon rank-sum tests are between 0.59 and 1). Considering bids in the IPO instead of market clearing prices leads to similar conclusions; bids submitted by individuals in the IPO are described in Appendix E.

\subsection{Market Prices in All Periods}

We now consider for all periods in a round the extent to which prices deviate from fundamentals. Specifically, we consider two measures of the deviation of bond prices from fundamental values - the relative absolute deviation (RAD) and the relative deviation (RD). The original formulas for RAD and $\mathrm{RD}$ are given by

$$
R A D_{\text {original }}=\frac{1}{T} \frac{\sum_{t=0}^{T}\left|M_{t}-V_{t}\right|}{\bar{V}} \text { and } R D_{\text {original }}=\frac{1}{T} \frac{\sum_{t=0}^{T} M_{t}-V_{t}}{\bar{V}},
$$

where $M_{t}$ stands for the market price in period $t, T$ for the total number of periods (in this experiment market prices can arise in periods 0 to $T-1), V_{t}$ for the fundamental value in period $t$ and $\bar{V}$ for the average of the fundamental values in all periods (see Stöckl et al., 2010). ${ }^{16}$ RAD measures mispricing; both positive and negative deviations of the market price from the fundamental value $V_{t}$ increase this measure. RD measures overvaluation; market prices above the fundamental lead to a higher measure, while market prices below the fundamental lead to a lower measure.

For our purposes, we have to extend these formulas, because they assume that there is trade in every period. We do so as follows (note that whenever there is trade in all periods, the extended formulas yield exactly the same results as the original formulas):

$$
R A D_{\text {extended }}=\frac{1}{T^{*}} \frac{\sum_{\{t \mid \text { trade in } t\}}\left|M_{t}-V_{t}\right|}{\bar{V}^{*}} \text { and } R D_{\text {extended }}=\frac{1}{T^{*}} \frac{\sum_{\{t \mid \text { trade in } t\}} M_{t}-V_{t}}{\bar{V}^{*}}
$$

where $T^{*}$ is the number of periods in which there is trade and thus a market price and $\bar{V}^{*}$ is the average of the fundamental values in the periods in which there is trade. Note that in our bond market setting the fundamental value after the IPO depends on the

\footnotetext{
${ }^{15}$ The same Wilcoxon signed-rank tests of whether IPO prices are different from the equilibrium value in rounds 2 and 3 yield $p$-values of 0.021 and 0.023 in $D E C$ and 0.020 and 0.059 in $I N C$, respectively.

${ }^{16}$ Stöckl et al. (2010) introduce these measures for continuous double auctions without a uniform market price, therefore they use the average of market prices per period $\bar{M}_{t}$ instead of $M_{t}$.
} 
IPO price achieved in the same market. In the remainder of this paper, RAD and RD always refer to these extended formulas.

Figure 7 shows the empirical cumulative distribution functions of RAD and RD for both of our treatments. Each circle or triangle corresponds to the RAD or $\mathrm{RD}$ of one group in one round. ${ }^{17}$ The graph of RAD suggests at most minor differences in the extent of mispricing between the two treatments. However, the graph of $\mathrm{RD}$ suggests that overpricing is relatively greater in the $D E C$ treatment as compared with the $I N C$ treatment. Together, these results imply that, while prices are similarly accurate across the two treatments they are more often too high in $D E C$ as compared with $I N C$. The mean values of RAD and RD across all groups (as shown in Table 2) confirm this observation.
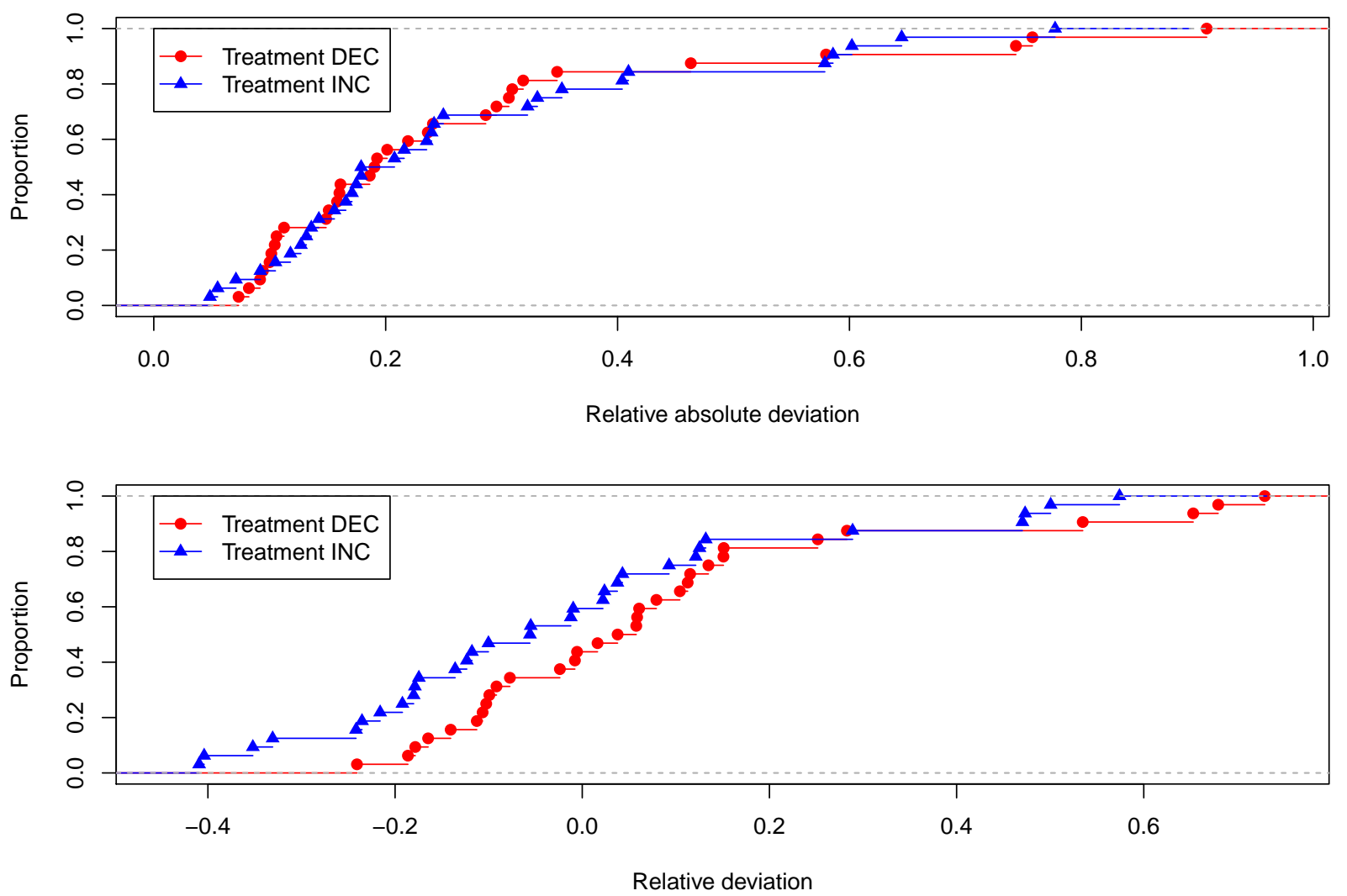

Figure 7: Empirical Cumulative Distribution Functions of RAD and RD

Notes: The graphs show RAD (top) and RD (bottom) in both treatments. Each circle or triangle represents the RAD or RD of one group in one round.

The table shows a clear downward trend for RAD, as subjects learn to price the bonds

\footnotetext{
${ }^{17}$ The observations of different groups are statistically independent. The observations of one group across different rounds should in general not be treated as statistically independent, but the summarizing empirical cumulative distribution functions shown in Figure 7 nevertheless provide a good illustration of what is going on. Considering the empirical cdf's separately for each round yields a similar picture.
} 
Table 2: Means RAD and RD

\begin{tabular}{ccccccc}
\hline & & Round 1 & Round 2 & Round 3 & Round 4 & mean R1-R4 \\
\hline \multirow{2}{*}{$\mathrm{RAD}$} & $D E C$ & 0.400 & 0.274 & 0.208 & 0.171 & 0.263 \\
& $I N C$ & 0.324 & 0.312 & 0.236 & 0.184 & 0.264 \\
\hline \multirow{2}{*}{$\mathrm{RD}$} & DEC & 0.158 & 0.124 & 0.054 & -0.002 & 0.084 \\
& INC & 0.022 & 0.097 & -0.102 & -0.095 & -0.019 \\
\hline
\end{tabular}

Notes: This table shows the means of RAD and RD across groups for each of the treatments.

better with experience. This downward trend persists when looking at the groups separately rather than at the means across all groups. When comparing the differences in $\mathrm{RAD}$ between the fourth and the first round for each group, a two-sided Wilcoxon signed-rank test rejects the null-hypothesis that mispricing is as large in the fourth round as in the first round in $D E C$ with a $p$-value of 0.039 . In treatment $I N C$, the majority of groups also price the bonds better in the fourth than in the first round. This difference is not statistically significant, however (with a $p$-value of 0.461 ). When pooling both treatments, a two-sided Wilcoxon signed-rank test rejects the null-hypothesis of equally accurate pricing in the first and the last round with a $p$-value of 0.044 in favor of the alternative hypothesis that prices are closer to fundamentals in the last round.

When looking at $\mathrm{RD}$ in Table 2, there is a slight tendency to price bonds lower in later rounds. This tendency can be attributed to fewer bubbles appearing (as noted above we do not observe bubbles in the last round). Overall, five of the eight groups in $D E C$ value bonds lower in the last round than in the first one, while three of the groups value bonds higher. In treatment $I N C$, six groups value bonds lower in the last round while two groups value them higher. These differences are not statistically significant, however, when examining differences in $\mathrm{RD}$ between the last and the first round with a Wilcoxon signed-rank test separately for each treatment ( $p$-values for DEC and INC are 0.195 and 0.250 , respectively). The differences are marginally significant when the data of both treatments is pooled (with a $p$-value of 0.074). Furthermore, the average RD over the four rounds is not statistically different between treatments (with a $p$-value of 0.279 when tested with a two-sided Wilcoxon rank-sum test).

A comparison of the bond pricing over the lifespan of a bond in our experiment to the findings of previous asset market experiments without an IPO shows that the results are qualitatively similar. In particular, pricing in this more complicated bond market setting is no worse than the pricing in markets with arguably simpler assets. In addition, our findings suggest that the development of the fundamental value is not of great 
importance for the functioning of experimental bond markets.

\subsection{Further Outcomes}

\subsubsection{Defaults}

In this experiment, default probabilities are determined by the IPO prices (the larger the IPO price the lower the default probability). Any order statistic of default probabilities is therefore the same as for IPO prices. Actual defaults are a noisy representation of default probabilities.

The numbers of defaults are very different between the two treatments as the treatment with increasing fundamental values features higher default probabilities by design. In $D E C$ there are overall 10 defaults in 32 markets (i.e., in 4 rounds of 8 independent groups). This means that in 10 markets the bond issuer defaults in one of the periods 1-10. In $I N C$ there are 29 defaults in 32 markets. Recall that defaults have no influence on the data we collect because of the block design described in Section 4 .

Of course, defaults naturally have an influence on payoffs. Furthermore, while the timing of defaults in previous rounds should not matter in a rational world for subsequent rounds, the occurrence of a default, and the time period in which it occurred, could affect subjects' behavior and market outcomes in subsequent rounds. This reaction to defaults could occur, because subjects receive feedback on whether and when there was a default in a round after the round ends (see Figure 3). Our data, however, show no evidence of such spillover effects. Figure 8 shows round-to-round changes in prices as a function of whether there was a default in period $k=1, \ldots 10$ of the previous round. More precisely, the round to round change in the overvaluation of prices relative to fundamentals as measured by $\mathrm{RD}$ is shown on the vertical axis and the period of default in the earlier of the two compared rounds is shown on the horizontal axis. Crosses instead of circles are for the case where no default occurred in the previous round. Each circle or cross thus represents the price change of one group (there are three such observations per group). For example, one circle shows one group's change in RD from round 1 to round 2 on the vertical axis and the default period in round 1 on the horizontal axis. If prices were to react negatively to an early-period default in the previous round, there would be a positive relationship between the prior round default period and the price change. As Figure 8 makes clear, there is no evidence for such behavior in either the $D E C$ or the $I N C$ treatments. 


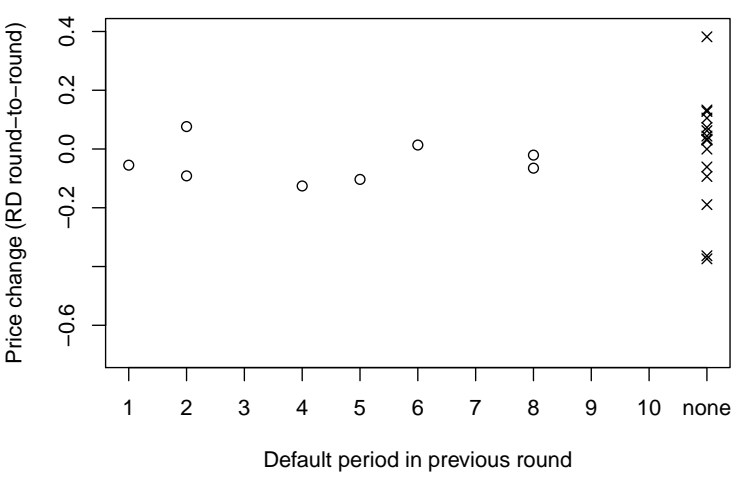

(a) Treatment $D E C$

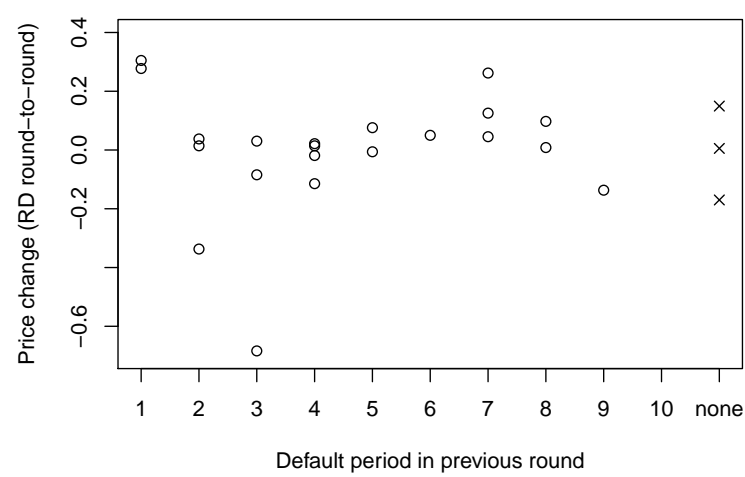

(b) Treatment INC

Figure 8: Defaults and Price Changes

Notes: Each circle or cross in the graph shows the change of prices from one round to the next on the $y$-axis for one group. On the $x$-axis is the period in which the bond issuer defaulted in the respective group's previous round (i.e. the round from which the price change is computed). For example, one circle shows one group's change in RD from round 2 to round 3 on the $y$-axis and the default period in round 2 on the $x$-axis.

\subsubsection{Traded Quantities}

For all groups and all rounds, the IPO always resulted in all 25 bonds being sold. Following the IPO of each round, there is no longer an opportunity to 'earn money from the experimenter'; that is the earnings any given subject makes (in expectation) from trading in periods 1-9 represent a loss (in expectation) for some other subject in the same group. Therefore, it is not surprising that the number of trades per period is much lower in these regular trading periods. Nevertheless, there is sustained trade in most groups with an average number of roughly two trades per period. There is no indication that the number of trades is different in the two treatments. Across rounds, the average number of trades per period decreases slightly but continuously, which can be interpreted as evidence for learning as subjects come to realize that trading in the regular periods does not lead to joint positive earnings. The average number of trades per period decreases in $D E C$ from 2.60 in round 1 to $2.18,1.64$, and 0.76 . The average number of trades in $I N C$ is 2.74 in round 1 and $2.10,1.26$, and 1.38 in rounds 2 to 4 . Naturally, there are many more bids and offers in each period then there are trades. Figures 18 and 19 in the Appendix D show the traded quantities in all rounds and periods for all groups. 


\section{Conclusion}

The pricing of bonds subject to default risk is more complicated than the pricing of other assets that experimentalists have studied in the laboratory. The complication lies mainly in the fact that the price of bonds in the initial public offering affects the probability of default, and this default risk in turn affects the initial pricing of the bond issue. In addition, bonds pay, aside from a periodic coupon payment, a maturity payment in the final round. In this paper we have developed a simple and tractable model of bond pricing based on the standard approach (Merton, 1974) in which bond purchasers must address these complications. We then evaluate whether experimental subjects who are incentivized to behave according to the theory are able to price the IPO of bonds correctly and in subsequent periods trade the bond at prices that approximate the fundamental value given the default risk that was determined by the IPO price. To our knowledge this is the first experimental test of the pricing of bonds subject to default risk.

While we would ideally like to examine how well traders price bonds subject to default risk in the field, the lack of control over important aspects of the theory such as the mapping between default risk and ipo price, as well as detailed knowledge of the IPO auction rules, the set of traders and the information available to those traders would lead to many confounding factors that would cloud such an analysis. The control of the laboratory allows us to abstract from such confounding factors, providing a clean test of the theory. Though the behavior of our human subjects (students) might be viewed as being less externally valid for understanding the pricing of bonds subject to default risk, note that previous tests of such subject pool effects in asset market experiments showed no differences between students and professionals (e.g., Smith et al., 1988; King et al., 1993).

Rather surprising to us, we find that with sufficient experience, subjects do learn to set an IPO price for bonds that is close to the equilibrium price of the theory. Moreover, we find that in subsequent trading periods, bond prices track fundamentals rather well, regardless of whether the time path for the bond's fundamental value is increasing, as in our INC treatment, or decreasing as in our DEC treatment. These findings demonstrate that market forces are strong enough to provide efficient pricing of risky bonds in spite of the complexities of these assets in comparison to other types of assets that have dominated the experimental finance literature. Thus our research suggests that experimentalists may also want to include bonds subject to default risk among the assets that they explore in future experimental tests of asset pricing theory, possibly in combination with more traditionally studied assets such as equities or risk free-bonds. 


\section{References}

Amato, J. D. and Remolona, E. M. (2003). The credit spread puzzle. BIS Quarterly Review, December:51-63.

Bosch-Rosa, C., Meissner, T., and Bosch i Domènech, A. (2015). Cognitive bubbles. Available at SSRN 2553230.

Bossaerts, P. (2009). The experimental study of asset pricing theory. Foundations and Trends in Finance, 3(4):289-361.

Bossaerts, P., Ghirardato, P., Guarnaschelli, S., and Zame, W. R. (2010a). Ambiguity in asset markets: Theory and experiment. Review of Financial Studies, 23(4):13251359.

Bossaerts, P., Ghirardato, P., Guarnaschelli, S., and Zame, W. R. (2010b). Ambiguity in asset markets: Theory and experiment. Review of Financial Studies, 23(4):13251359.

Bossaerts, P., Plott, C., and Zame, W. R. (2007). Prices and portfolio choices in financial markets: Theory, econometrics, experiments. Econometrica, 75(4):993-1038.

Breaban, A. and Noussair, C. N. (2014). Fundamental value trajectories and trader characteristics in an asset market experiment. CentER Discussion Paper.

Cheung, S. L., Hedegaard, M., and Palan, S. (2014). To see is to believe: Common expectations in experimental asset markets. European Economic Review, 66:84-96.

Cheung, S. L. and Palan, S. (2012). Two heads are less bubbly than one: team decisionmaking in an experimental asset market. Experimental Economics, 15(3):373-397.

Crockett, S. and Duffy, J. (2015). An experimental test of the lucas asset pricing model. Working Paper.

Dufwenberg, M., Lindqvist, T., and Moore, E. (2005). Bubbles and experience: An experiment. The American Economic Review, 95(5):1731-1737.

Fischbacher, U., Hens, T., and Zeisberger, S. (2013). The impact of monetary policy on stock market bubbles and trading behavior: Evidence from the lab. Journal of Economic Dynamics and Control, 37(10):2104-2122.

Fréchette, G. R. and Yuksel, S. (2013). Infinitely repeated games in the laboratory. Working Paper. 
Füllbrunn, S., Neugebauer, T., and Nicklisch, A. (2014a). Underpricing of initial public offerings in experimental asset markets.

Füllbrunn, S., Rau, H. A., and Weitzel, U. (2014b). Does ambiguity aversion survive in experimental asset markets? Journal of Economic Behavior \& Organization, 107:810826.

Giusti, G., Jiang, J. H., and Xu, Y. (2014). Interest on cash, fundamental value process and bubble formation on experimental asset markets. Bank of Canada Working Paper.

Gneezy, U., Kapteyn, A., and Potters, J. (2003). Evaluation periods and asset prices in a market experiment. The Journal of Finance, 58(2):821-838.

Haruvy, E., Lahav, Y., and Noussair, C. N. (2007). Traders' expectations in asset markets: experimental evidence. The American Economic Review, 97(5):1901-1920.

Haruvy, E. and Noussair, C. N. (2006). The effect of short selling on bubbles and crashes in experimental spot asset markets. The Journal of Finance, 61(3):1119-1157.

Huber, J. and Kirchler, M. (2012). The impact of instructions and procedure on reducing confusion and bubbles in experimental asset markets. Experimental Economics, 15(1):89-105.

Hull, J., Predescu, M., and White, A. (2005). Bond prices, default probabilities and risk premiums. Journal of Credit Risk, 1(2):53-60.

King, R. R., Smith, V. L., Williams, A. W., and van Boening, M. V. (1993). The robustness of bubbles and crashes in experimental stock markets. In Day, R. H. and Chen, P., editors, Nonlinear Dynamics and Evolutionary Economics, pages 183-200. Oxford University Press, New York.

Kirchler, M. (2009). Underreaction to fundamental information and asymmetry in mispricing between bullish and bearish markets. an experimental study. Journal of Economic Dynamics and Control, 33(2):491-506.

Kirchler, M., Huber, J., and Stöckl, T. (2012). Thar she bursts: Reducing confusion reduces bubbles. The American Economic Review, 102(2):865-883.

Merton, R. C. (1974). On the pricing of corporate debt: The risk structure of interest rates. The Journal of Finance, 29(2):449-470.

Noussair, C., Robin, S., and Ruffieux, B. (2001). Price bubbles in laboratory asset markets with constant fundamental values. Experimental Economics, 4(1):87-105. 
Noussair, C. N. and Powell, O. (2010). Peaks and valleys: Price discovery in experimental asset markets with non-monotonic fundamentals. Journal of Economic Studies, $37(2): 152-180$.

Noussair, C. N. and Tucker, S. (2013). Experimental research on asset pricing. Journal of Economic Surveys, 27(3):554-569.

Palan, S. (2010). Digital options and efficiency in experimental asset markets. Journal of Economic Behavior \& Organization, 75(3):506-522.

Palan, S. (2013). A review of bubbles and crashes in experimental asset markets. Journal of Economic Surveys, 27(3):570-588.

Smith, V. L., Suchanek, G. L., and Williams, A. W. (1988). Bubbles, crashes, and endogenous expectations in experimental spot asset markets. Econometrica, 56(5):1119-1151.

Stöckl, T., Huber, J., and Kirchler, M. (2010). Bubble measures in experimental asset markets. Experimental Economics, 13(3):284-298.

Stöckl, T., Huber, J., and Kirchler, M. (2014). Multi-period experimental asset markets with distinct fundamental value regimes. Experimental Economics, 18(2):314-334.

Sutter, M., Huber, J., and Kirchler, M. (2012). Bubbles and information: An experiment. Management Science, 58(2):384-393.

Zhang, P. (2009). Uniform price auctions and fixed price offerings in IPOs: An experimental comparison. Experimental Economics, 12(2):202-219. 


\section{A Appendix (for Online Publication): Instructions}

In the following we reproduce the instructions of the treatment with decreasing fundamentals. The instructions of the treatment with increasing fundamentals are similar, only the numbers are correspondingly different (as described in Section 4), of course also leading to a different graph of the default probability function. This graph, a table with values, and a short summary of the information, which is shown at the end of the instructions, is reproduced for the treatment with increasing fundamentals in Section A.2.

\section{A.1 Instructions in the Decreasing Fundamentals Treatment}

\section{Instructions}

Welcome to this experiment! Please read these instructions carefully as they explain how you earn money from the decisions that you make. You will be paid privately at the end, after all participants have finished the experiment. On your desk you will find a calculator and scratch paper, which you can use during the experiment.

During the experiment you are not allowed to use your mobile phone or other electronic devices. You are also not allowed to communicate with other participants. If you have a question at any time, please raise your hand and someone will come to your desk.

The experiment consists of four identical rounds. Each round consists of 11 periods, numbered from 0 to 10 . Your earnings for each of the four rounds will be in points. At the end, only your earnings from one randomly chosen round will be paid out to you! The points from the chosen round will be exchanged into euros at the exchange rate 1000 points $=1$ euro. In addition you will receive a show-up fee of 7 euros.

All participants will be randomly divided into groups of 6 people. The group composition will not change during the experiment. You will not know the identity of any group member nor will they know your identity even after the experiment is over. The following describes what you will be doing in each of the four rounds.

\section{Market Setting}


You will start the round with an endowment of 20000 points (your "cash"). During most of the experiment, you will be given an opportunity to trade an asset with the other participants in your group (called "asset A" - there are no other assets). In total there are 25 assets.

Holding assets can give you earnings in a way that will be explained below.

If you want to buy some of these assets you can enter the number of assets you want to buy (bid for) at a certain price using the computer interface. You can state as many different bid prices and quantities as you like.

Example (the numbers here provide no indication of what you should enter in the experiment): Imagine that you would like to buy 12 assets if the price per asset is at most 356 points, 7 assets if the price is larger than 356 but no more than 688 points, and only 2 assets if the price is larger than 688 points but no more than 911.5 points. To indicate this, you can enter numbers into the computer interface as follows (if you wanted to enter more numbers you could click on the "show more fields" button):

Figure 9 appears here in the experimental instructions.
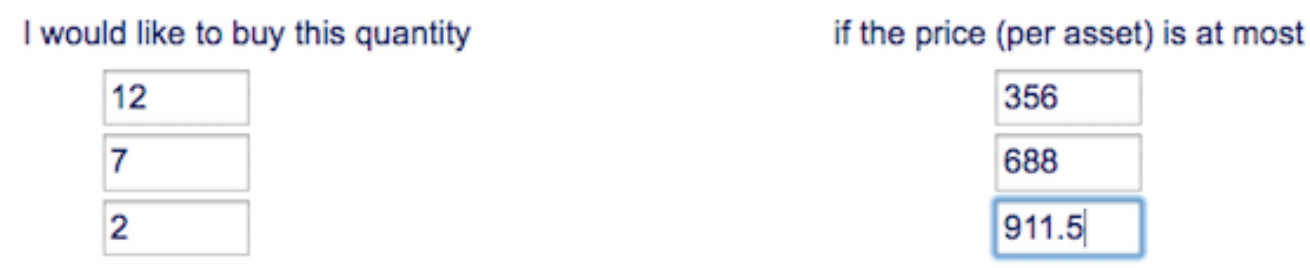

show more fields

Figure 9: Input fields of the computer interface (not labeled in the instructions)

If the market price turns out to be 600 points, you will then receive 7 assets for 600 points each (thus NOT 2 plus 7, i.e. the quantities that you enter are for the total number you want to buy at a certain price).

If you want to sell assets you previously bought, you can do something similar. You can enter the number of assets that you want to sell (offer quantity) and the offer price that you would like to receive for those units (the interface will be almost identical to the buying example above). You can again enter multiple combinations of quantities and prices. 
The bids and offers that you can enter into the computer interface are restricted as follows:

- You can only enter positive integer number as quantities.

- You can only enter positive numbers as prices (if you want to enter a decimal, use a point and not a comma).

- You cannot try to sell more assets than you have at that moment. Similarly, you cannot try to buy more assets than there are available (which is 25 minus the number of assets you have).

- You cannot enter bids that you would not be able to pay for (with the amount of cash you have).

- You cannot enter multiple bids to buy assets with the same quantity or the same price.

- Similarly you cannot enter multiple offers to sell assets with the same quantity or the same price.

- You cannot try to buy more assets for a higher price than you would want to buy for a lower price (i.e., if you enter for example the quantity 20 with the price 1850 , you cannot enter the quantity 10 with the price 1480 in the fields for your bids to buy assets).

- Similarly you cannot try to sell more assets at a lower price than you would sell at a higher price.

- Finally, all of your selling offers must be at a higher price than your buying bids (i.e. you cannot sell to yourself).

\section{Market Price and Actual Trades}

The market price in each period is determined by supply and demand. This means that the price will be chosen that makes the most trades possible. All trades are then carried out at this single market price, which is centrally determined for your group in each period.

Explanation: Imagine you enter that you would like to buy 6 assets if the price is at most 1500 points and one other participant enters that she would like to buy 9 assets if the price is at most 1500. Imagine further that nobody else in the market enters a buying bid at 1500 points or a higher price. This means that all participants of the market together would like to buy 15 assets if the price is at most 1500 points per asset. The aggregation of the buy orders can be done for all prices and yields the market demand schedule. This demand schedule contains the information of all buy orders 
for all participants of the market together and can be represented by a step function as below. On the horizontal axis you can see the total quantity demanded for each price on the vertical axis (this is a very simple example and the quantities and numbers provide no indication of what you should enter in the experiment). In the graph of this simple example you can see that all participants of the market together are willing to buy up to 75 assets at a price of 500 points per asset, only 50 assets at a price of 1000 points per asset, and only 15 assets at a price of 1500 points per asset.

Figure 10 appears here in the experimental instructions.

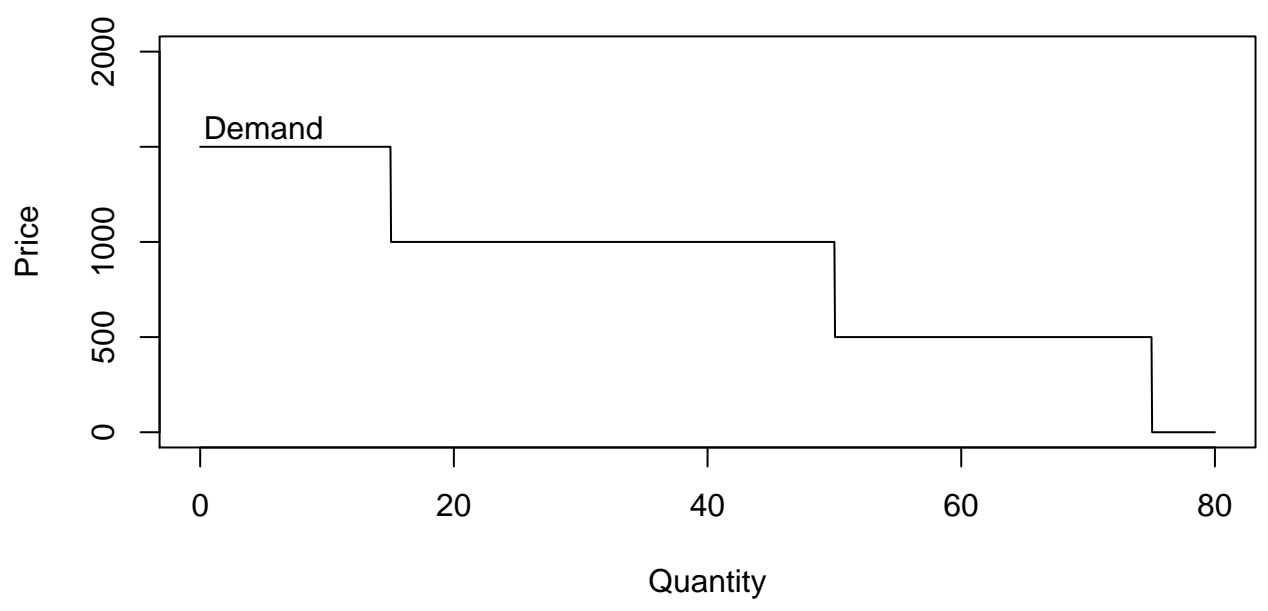

Figure 10: Demand schedule (not labeled in the instructions)

A similar schedule can be derived for the supply side of the market, aggregating all the sell offers. When drawn in the same graph, the supply schedule is an increasing step function.

Figure 11 appears here in the experimental instructions.

The market price is the price at which the two curves intersect (in this example 1000). Note that at this price, 10 more assets are demanded than supplied (50 assets are demanded while only 40 are supplied). In this case a random selection of 10 bids from all the bids at the market price would not be fulfilled (it is similarly possible that there is more supply at the market price than demand).

In some rare cases there can also be a whole interval of prices at which most trades can be carried out (then the demand and supply schedule overlap vertically). In such cases the middle of the interval will be the market price. If no bids or offers are made at all 


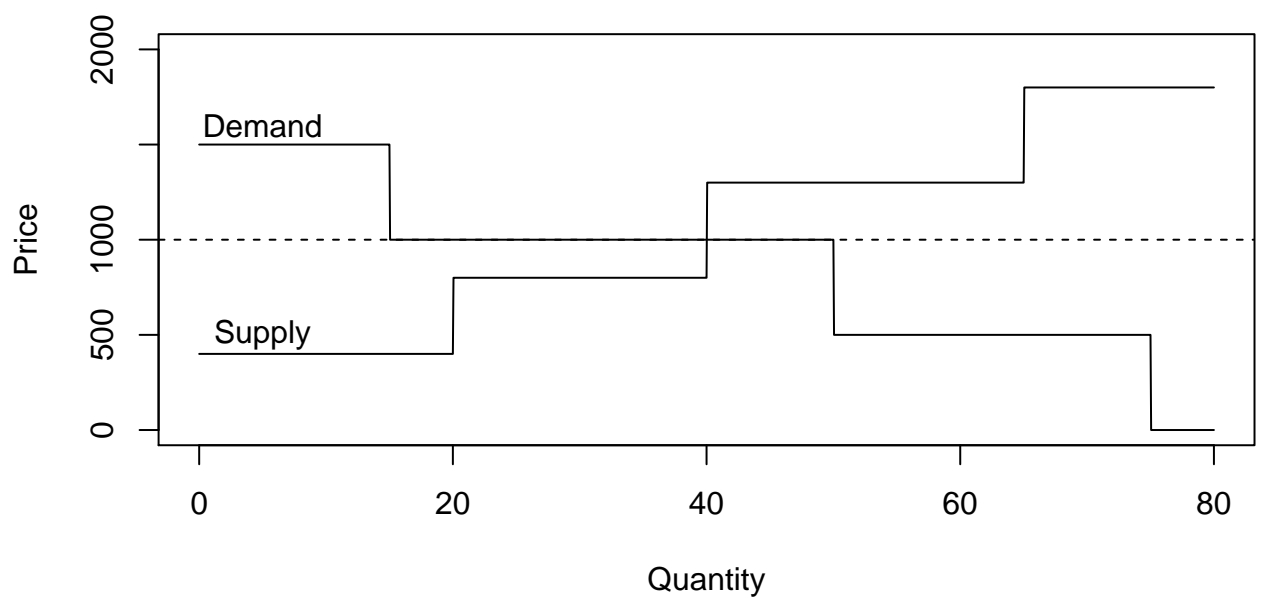

Figure 11: Demand and supply schedules (not labeled in the instructions)

or if all bids to buy are at lower prices than all offers to sell there will be no trade and also no market price.

You will always be told the market price after the trading. You will not be told the total number of trades in the market (except if there are none).

\section{Properties of the Asset}

There will be no trading in period 10. If you hold assets in period 10, you will receive 1000 points for each asset, provided that the asset has not defaulted (more on this below).

In each of periods 1-10 you receive interest payments on your asset holdings (if they have not defaulted). The interest payment per asset is $12 \%$ of the final value (1000 points), which means that you will receive 120 points for each asset you hold in a period. These earnings will be paid to a separate account - they are part of your earnings for the round, but you cannot use those points to buy more assets.

The asset you are trading has a special property. There is a constant possibility of "default". At the beginning of each period (from period 1 on to period 10) it is determined whether a default occurs or not. How this probability of default is determined will be explained shortly. If a default occurs, the assets will become completely (!) worthless for all periods remaining in the round. This means that from the period of default onward there will be no interest payments and there will be no payoff of 1000 points per asset after period 10 .

\section{Period 0 Trading and Probability of Default}


The first period of each round is a special period (period 0). In this period, none of the participants holds any of the 25 assets. You can try to buy them as in the regular periods $1,2, \ldots, 9$, but instead of buying them from other participants you will buy them directly from the experimenter. The computer interface is similar to the computer interface in the regular periods (i.e. you can enter the number of assets you want to buy at a certain price). The experimenter only sells assets in period 0 and does not interfere with the market thereafter. The experimenter will sell all assets in this period, for the highest unique price at which all of them can be sold (if there is not enough demand to sell all assets even at a minimal price, the experimenter will sell as many assets as are demanded).

The outcome of this period 0 is important not only because it distributes the assets amongst the participants in the group. It also determines the probability that the assets default in each of the other periods. The higher the market price is in period 0 , the lower is the probability that there will be a default (this probability is determined in period 0 and stays constant once period 0 is over). The following graph shows you the exact relationship between period 0 price and default probability. On the horizontal axis you can see possible period 0 prices and on the vertical axis you can see the default probability that would result from each price.

Figure 12 appears here in the experimental instructions.

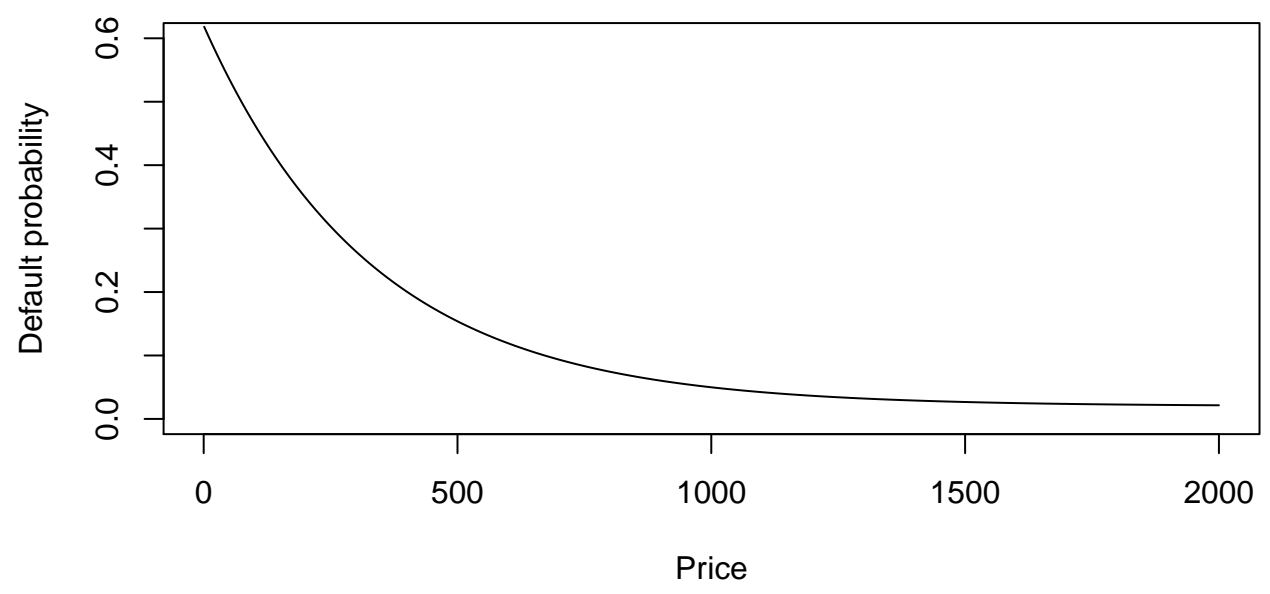

Figure 12: Default probability function, decreasing fundamentals (not labeled in the instructions)

The following short table gives you some period 0 prices and the corresponding default probabilities. 


\begin{tabular}{|c|c|c|c|c|c|c|c|c|c|c|c|}
\hline Price & 1 & 100 & 200 & 400 & 600 & 800 & 1000 & 1500 & 2000 & 3000 & 5000 \\
\hline Prob. & 0.618 & 0.464 & 0.349 & 0.201 & 0.119 & 0.074 & 0.050 & 0.027 & 0.021 & 0.020 & 0.020 \\
\hline
\end{tabular}

At the beginning of each of the regular periods, the computer program determines whether or not there is a default for the whole market using the default probability determined by the price in period 0 .

\section{Information on Defaults}

Although it will be determined at the beginning of each period whether there is a default in this period or not, we will not tell you whether or not a default has occurred! You will always continue the experiment as if no default has ever occurred only after each 10 period round we will tell you if there was a default or not and if so, in which period the (earliest) default occurred. Your earnings for that round are then determined as of the period the default occurred (your earnings are your cash holdings and the points earned in your interest account at the time of default - your assets at the time of default do not affect your earnings in any way). This means that any action you took after the default occurred does not affect your earnings (but when you take the decisions you don't know whether a default had previously occurred).

\section{Summary of the Information}

- 4 identical rounds

- 10 regular periods per round

- 20000 points cash to buy assets per round

- Period 0 is special and determines the default probability.

- If there is a default all assets become completely worthless. Earnings are based on interest payed before the default and cash holdings at the time of default.

- Each asset pays 120 points interest per period (if the asset is not in default).

- Points earned on assets in the interest account cannot be used to buy assets.

- If there is no default, then in period 10 each asset is exchanged for 1000 points.

- We don't tell you during a round if there is a default, you always continue as if there is none. However, the default is used to determine your round earnings. 


\section{A.2 Default Probability Function and Summary of the Information in the Increasing Fundamentals Treatment}

As noted above, in the instructions for the treatment with increasing fundamentals the numbers are different (see Section 4). Figure 13 shows the corresponding graph of the default probability function and Table 3 shows the corresponding table. Furthermore, we reproduce here the short summary at the end of the instructions.

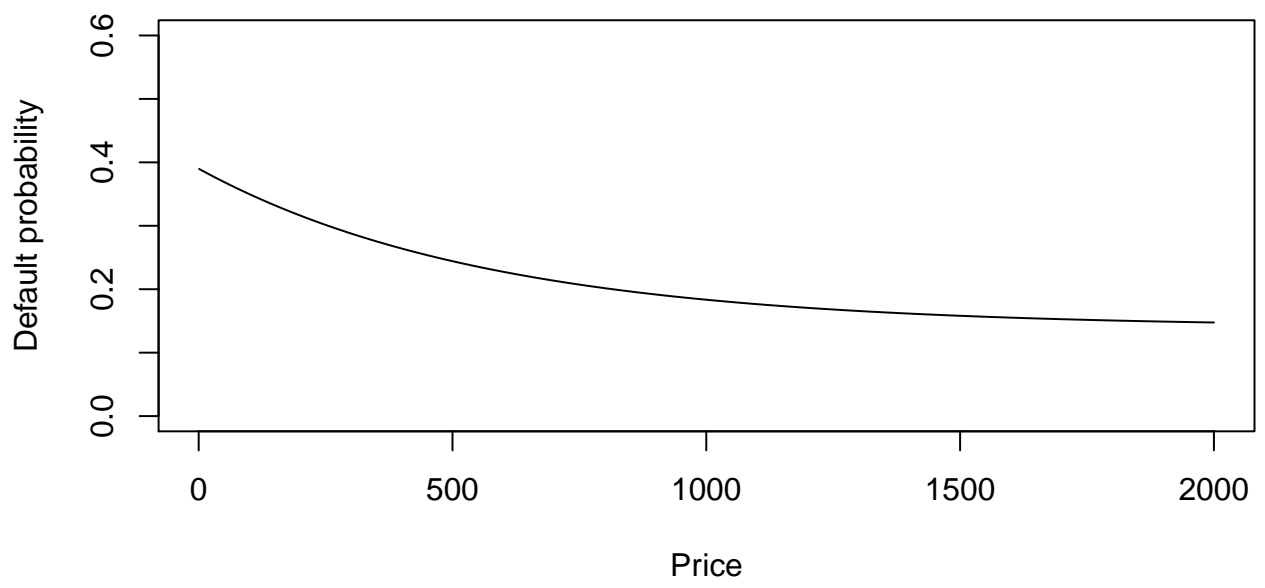

Figure 13: Default probability function, increasing fundamentals (instead of Figure 13 in the increasing fundamentals treatment)

\begin{tabular}{|l|c|c|c|c|c|c|c|c|c|c|c|}
\hline Price & 1 & 200 & 400 & 600 & 800 & 1000 & 1500 & 2000 & 3000 & 5000 & 10000 \\
\hline Prob. & 0.390 & 0.316 & 0.264 & 0.227 & 0.202 & 0.183 & 0.160 & 0.148 & 0.141 & 0.140 & 0.140 \\
\hline
\end{tabular}

Table 3: Table default probability function, increasing fundamentals

\section{Summary of the Information}

- 4 identical rounds

- 10 regular periods per round

- 20000 points cash to buy assets per round

- Period 0 is special and determines the default probability.

- If there is a default all assets become completely worthless. Earnings are based on interest payed before the default and cash holdings at the time of default. 
- Each asset pays 300 points interest per period (if the asset is not in default).

- Points earned on assets in the interest account cannot be used to buy assets.

- If there is no default, then in period 10 each asset is exchanged for 2500 points.

- We don't tell you during a round if there is a default, you always continue as if there is none. However, the default is used to determine your round earnings.

\section{B Appendix (for Online Publication): Test Questions}

The test questions that had to be answered by participants before they could start the experiment were the same in both treatments. They are reproduced here. We have added a checkmark behind the correct answers. Note that subjects had to answer all questions on one screen correctly in order to proceed to the next screen. If they did not answer all questions correctly and tried to proceed to the next screen they received the following error message: "You did not answer all questions correctly. Take another look at the instructions or raise your hand if you need help."

\section{B.1 Screen 1}

In period 0 , the experimenter tries to sell all 25 assets. Imagine that all of the other 5 participants in your market enter only one bid each and that all of their bids are equal, specifying a quantity of 2 and a price of 1500 . Imagine that you enter the following three bids:

Quantity 4 and Price 2000,

Quantity 8 and Price 900,

Quantity 25 and Price 50.

What will be outcomes of this?

(a) All others receive 2 assets each and pay a price of 1500 points per asset. You receive 15 assets, some for a higher price than 1500 points, some for a lower price.

(b) All others receive 2 assets each and you receive 15 assets. Everyone pays 50 points per asset. $\checkmark$

(c) All others receive 2 assets each and you receive 4 assets. Everyone pays 1500 points per asset. 
(d) All others receive 2 assets each and you receive 25 assets. Everyone pays 50 points per asset.

In period 0 , imagine that 4 of the other 5 participants in your market enter only one bid each and that all of their bids are equal, specifying a quantity of 5 and a price of 800. The fifth other participant and you both enter a quantity of 10 and a price of 600 . What will be outcomes of this?

(a) The market price will be 600. The 4 participants that entered the same bids receive 5 assets each, you and the person entering the same bid as you will receive 5 assets each.

(b) The market price will be 800 . The 4 participants that entered the same bids receive 5 assets each, you and the person entering the same bid as you will receive 5 assets each.

(c) The market price will be 600 . The 4 participants that entered the same bids receive 5 assets each, you and the person entering the same bid as you will receive 5 assets together (who receives how many exactly will be determined randomly).

(d) The market price will be 800 . The 4 participants that entered the same bids receive 5 assets each, you and the person entering the same bid as you will receive 5 assets together (who receives how many exactly will be determined randomly).

Imagine that you want to buy 25 assets in total if the price is at most 204 points per asset. If the price is larger than 204 points but at most 788 points you want to buy 13 assets in total. If the price is larger than 788 points but at most 1800.5 points you want to buy 8 assets. What do you enter into the corresponding part of the computer interface?

(a) Quantity: 25, Price 204, Quantity 13, Price 788, and Quantity 8, Price 1800.5. $\checkmark$

(b) Quantity: 8, Price 1800.5, Quantity 5, Price 788, and Quantity 12, Price 204.

\section{B.2 Screen 2}

In periods 1 to 9 you can trade the asset with the other members of your group. You can enter bids to buy assets and offers to sell assets. Imagine that you consider both, buying and selling assets. Which of the following is correct?

(a) You cannot try to buy assets at a higher price than the lowest price at which you are willing to sell assets. $\checkmark$ 
(b) You can try to bid for as many assets as you like at any price. If the market price turns out to be high, your cash holdings may become negative.

(c) You can make sell offers for the same quantity at different prices.

In the very beginning of each period from period 1 to 10 it will be determined whether there is a default. If there is a default, what happens to the assets?

(a) The assets will not pay any interest anymore for the remaining periods of this round. In the last period they will nevertheless be exchanged into 1000 points per asset.

(b) The asset will not pay any interest anymore for the remaining periods of the round and participants will not receive any points for the assets in the last period.

The default probability depends on the market price in period 0 . Which of the following is NOT correct?

(a) After period 0 has ended, the probability that there is a default is fixed for the rest of the round.

(b) You can see in the corresponding graph in the instructions how the price in period 0 determines the probability of default.

(c) When a new round starts, the default probability in the round before does not matter anymore for the new round.

(d) The default probability for each period is determined in the period before. $\checkmark$

Imagine that in period 6 you hold 7 assets. Other members of your group each offer to sell 3 units at a price of 1100 and ask to buy 6 units at a price of 1000 . You offer to sell 7 units at a price of 1151 and ask to buy 6 units at a price of 1149 . What trades are you involved in, in period 6 ?

(a) You sell 7 units at a price of 1151 .

(b) You sell 7 units at a price of 1149 .

(c) You sell 7 units at a price of 1100 .

(d) You sell 7 units at a price of 1000 .

(e) You buy 6 units at a price of 1000 .

(f) You buy 6 units at a price of 1100 .

(g) You buy 6 units at a price of 1149.

(h) You buy 6 units at a price of 1151 . 


\section{B.3 Screen 3}

If you hold assets at some point you may receive interest payments. Which of the following is correct?

(a) You can use the money from your interest account to buy assets in later periods.

(b) For each asset you are holding in a period you receive an interest payment of 120 points (if there has been no default before). $\checkmark$

(c) An asset only pays interest in the period right after you bought it, even if you hold it for multiple periods.

There are rounds and periods in this experiment. Which of the following is correct?

(a) There are 4 rounds in the experiment (each consisting of 10 regular periods and period 0). When you start a new round you have 20000 points in cash, 0 points in your interest account and no assets. $\checkmark$

(b) In each of the regular periods you have 20000 points of cash to buy assets with.

(c) Assets only last for one period, once the interest of an asset has been paid the asset always loses its value.

In each period there is the possibility of a default that makes all assets completely worthless. What happens when such a default occurs?

(a) You will immediately be informed that the default occurs, your earnings are determined and your group will continue straight with the next round.

(b) You will only be informed after the end of the round that this default occurred. Without you knowing it, the further actions you take during the rest of the round will no longer influence your earnings of the round. $\checkmark$

\section{Appendix (for Online Publication): Graphs of Prices in all Markets}

Figures 14 to 17 show the market prices in the experiment in all rounds and periods for all groups. Figures 14 and 15 show the prices for all eight groups in treatment $D E C$, Figures 16 and 17 show the prices for the eight groups in treatment INC. Each row corresponds to one group, starting with the first round on the left and ending with the fourth round on the right. Market prices are shown with red circles. Red crosses 
show the mean of the highest bid and the lowest offer price when no trade is carried out but when both bids and offers are present. Similarly to Figure 2, the equilibrium fundamental value is drawn with a solid black line and the price leading to the highest possible expected earnings for all subjects together is drawn with a dashed black line. Furthermore, the actual fundamental value within a round (which depends on the price in the IPO and is different across groups and rounds) is drawn with a dotted blue line. As there is no more trade in the tenth period, periods only reach from 0 (the IPO) to 9. 

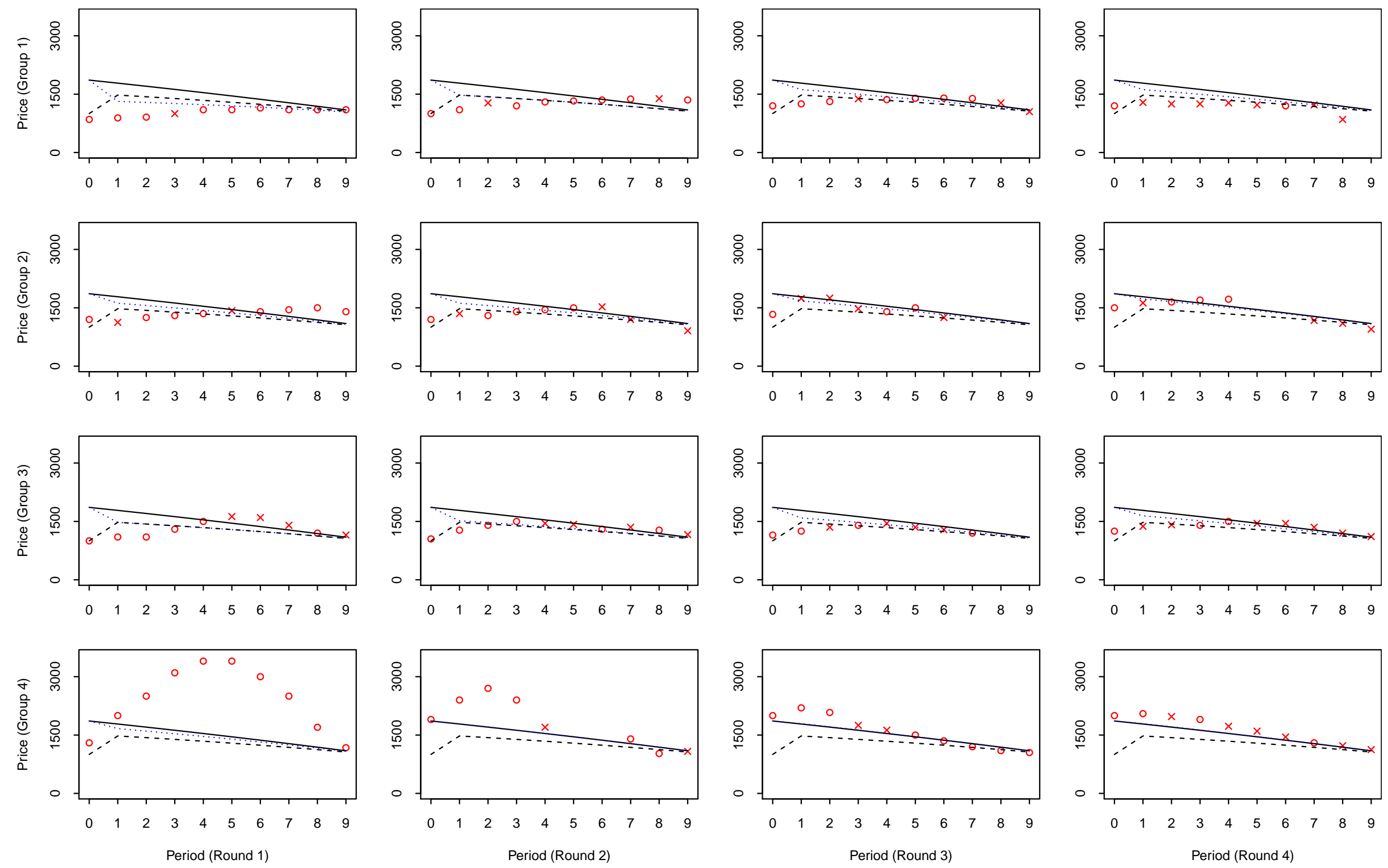

Figure 14: Prices in all Periods and Rounds, Groups 1 to 4, Treatment DEC 

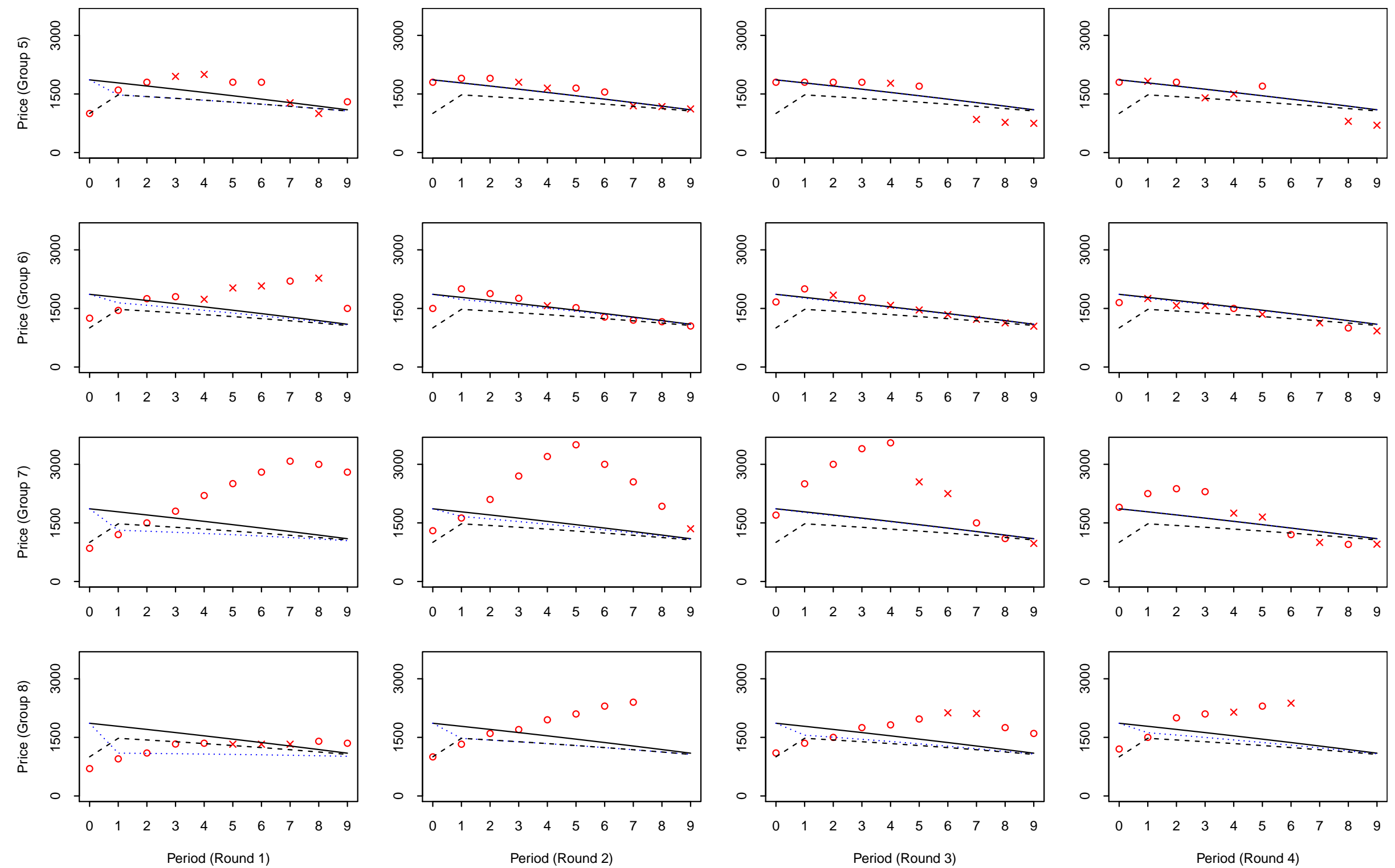

Figure 15: Prices in all Periods and Rounds, Groups 5 to 8, Treatment $D E C$ 

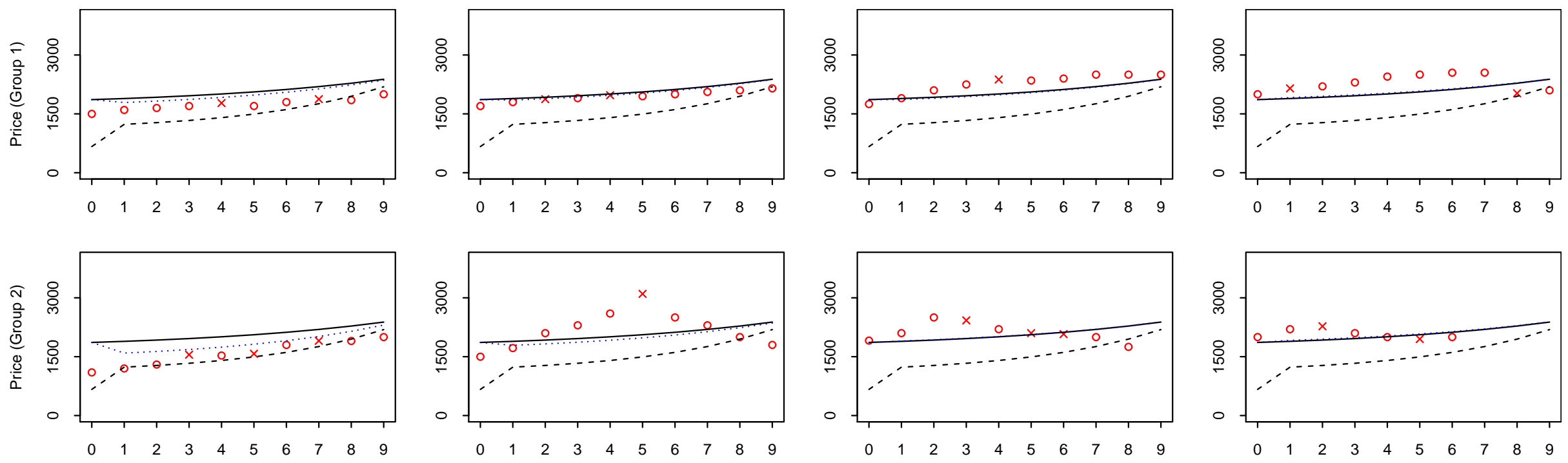

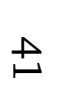
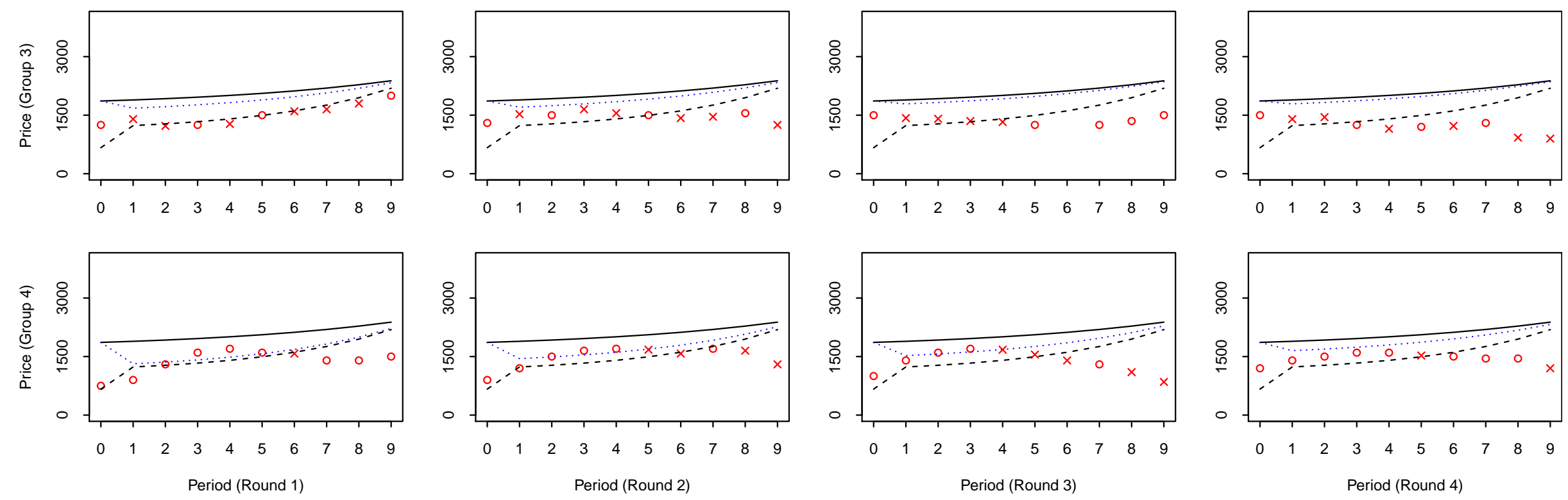

Figure 16: Prices in all Periods and Rounds, Groups 1 to 4, Treatment $I N C$ 

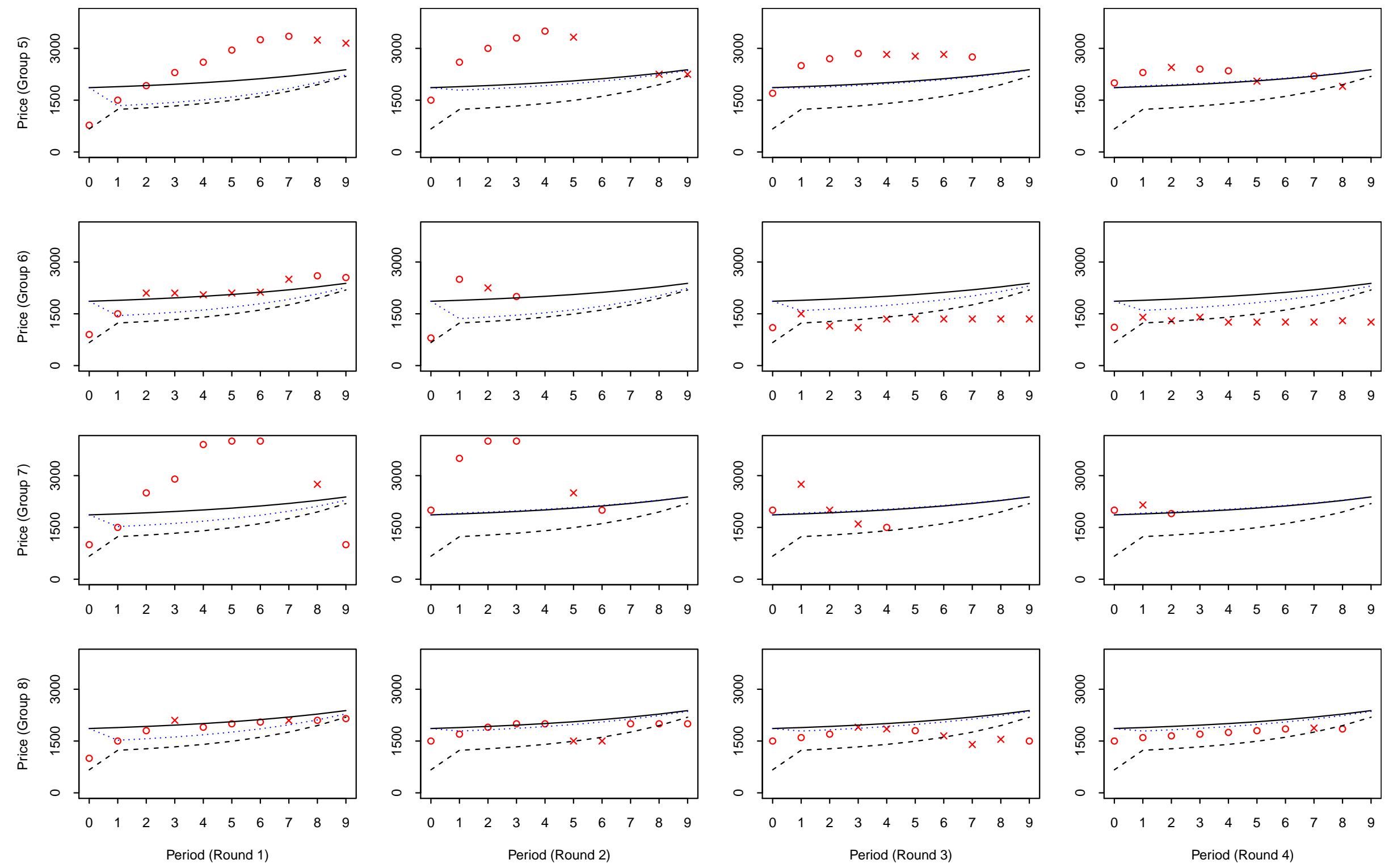

Figure 17: Prices in all Periods and Rounds, Groups 5 to 8, Treatment $I N C$ 


\section{Appendix (for Online Publication): Graphs of Traded Quantities}

Figures 18 and 19 show the quantities traded in the different groups in all rounds and all regular periods (in period 0, i.e. in the IPO always all 25 bonds are sold). Each line connects the quantity traded in the different periods of the same round. Figure 18 shows the data from the groups in treatment $D E C$, while Figure 19 shows the data from the groups in treatment $I N C$. 

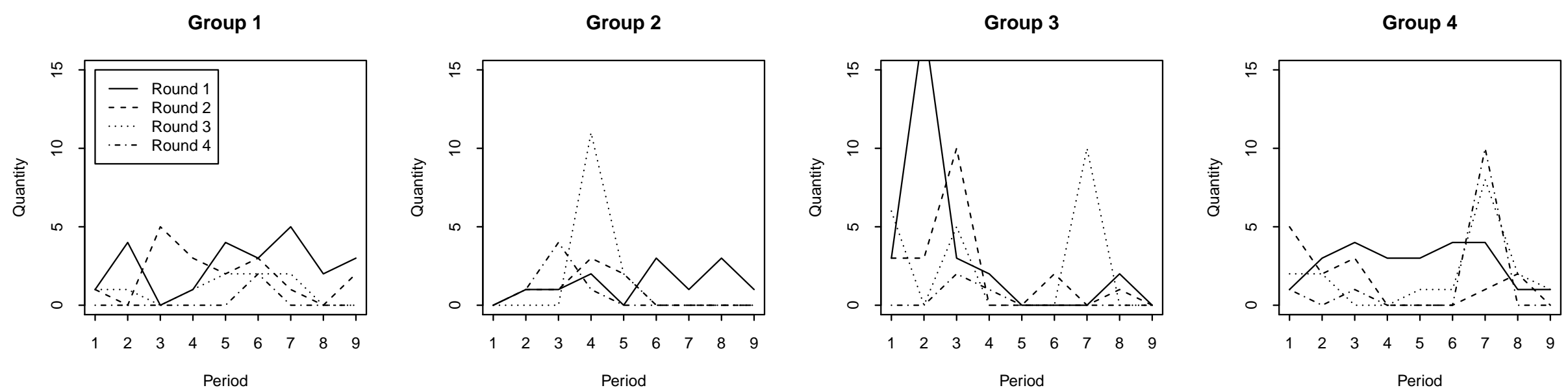

$\stackrel{A}{+}$
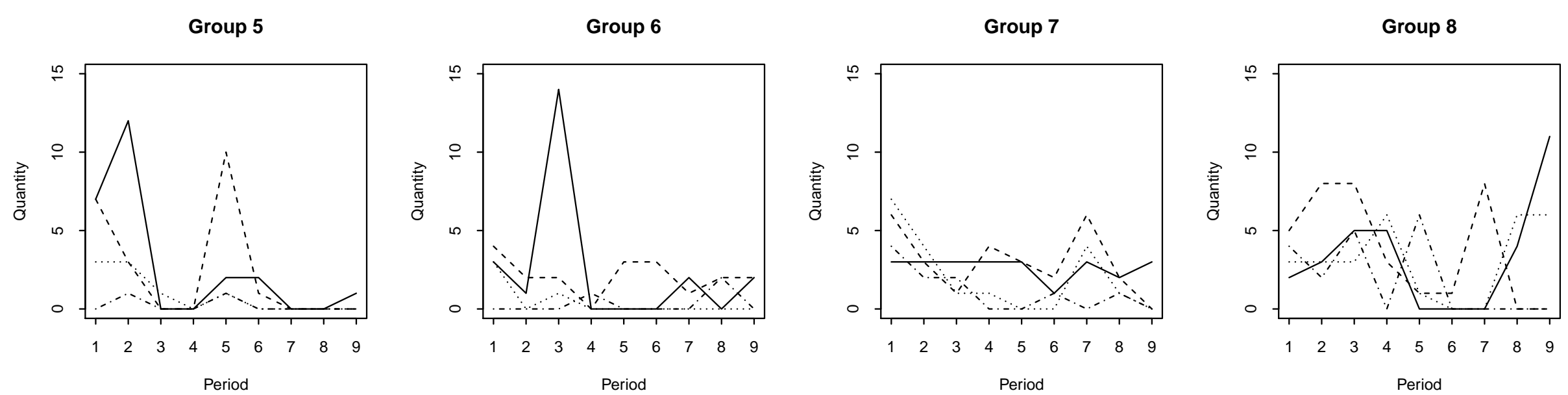

Figure 18: Quantities Traded in Treatment DEC 


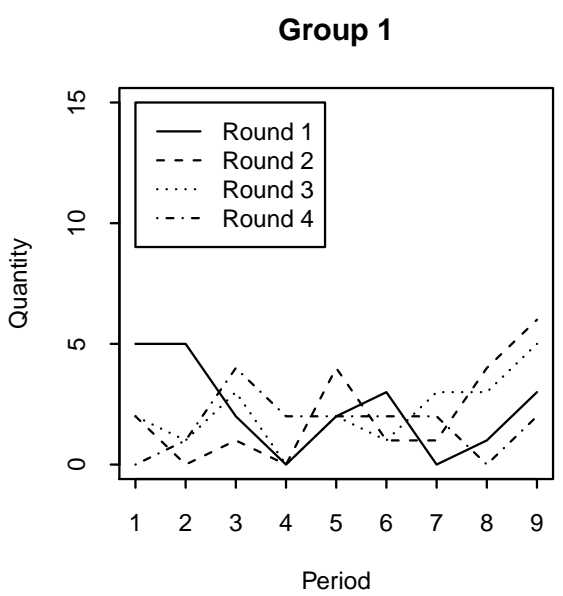

c

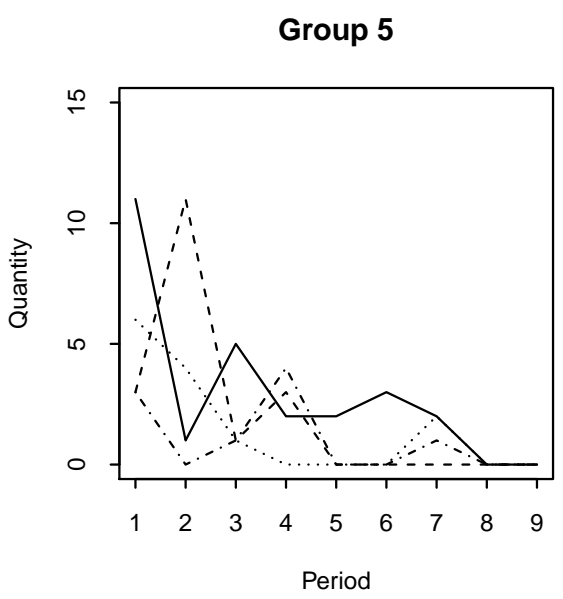

Group 2

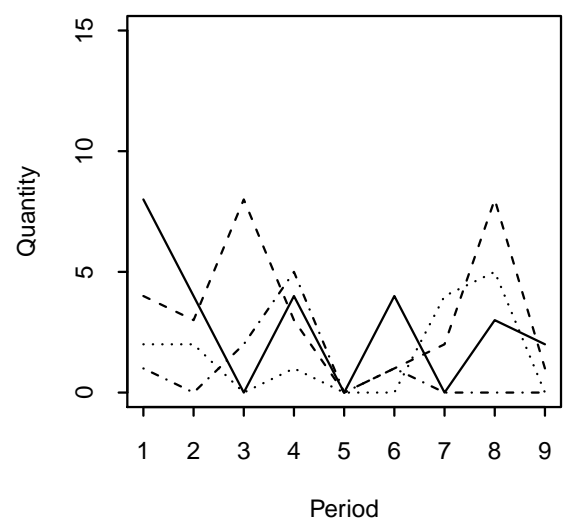

Group 6

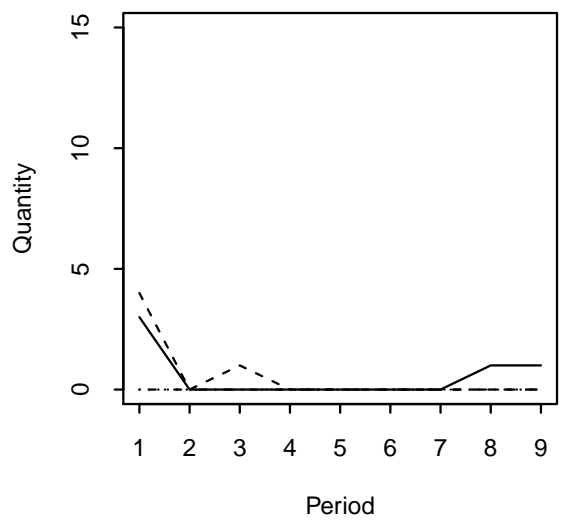

Group 3

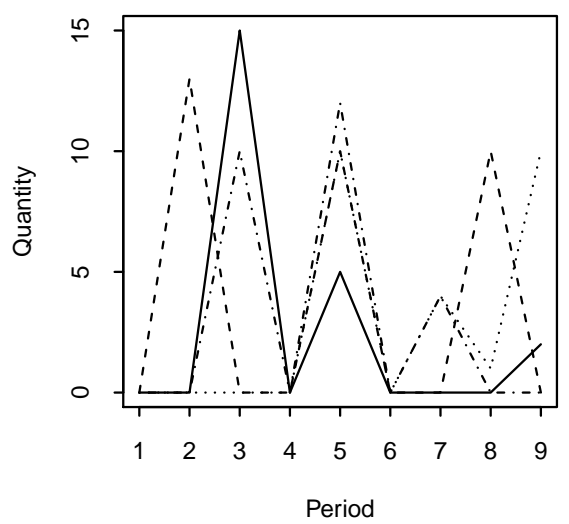

Group 7

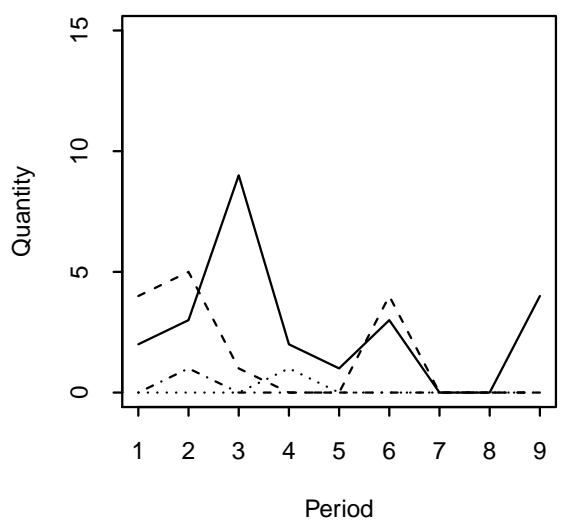

Group 4

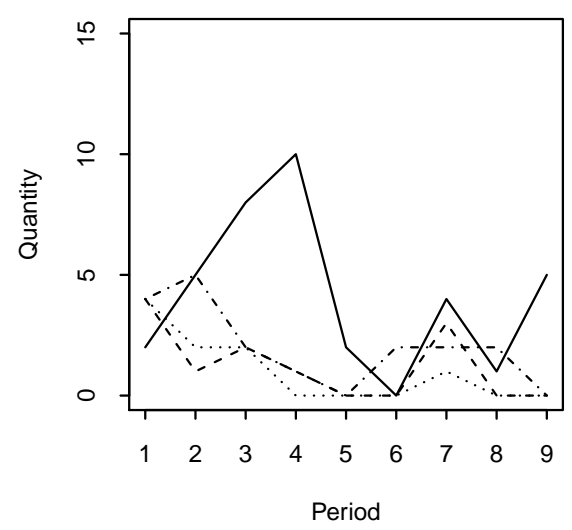

Group 8

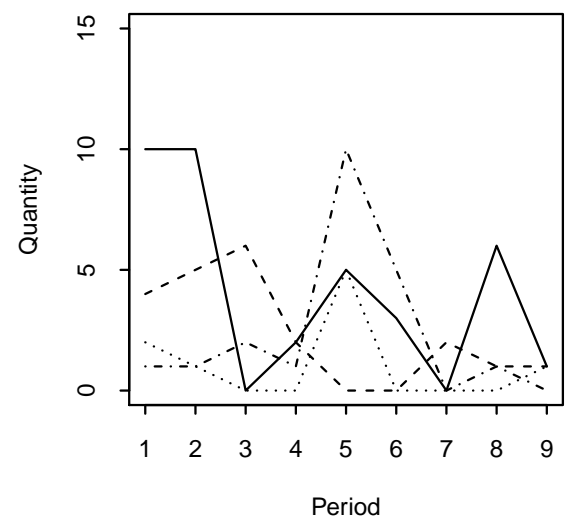

Figure 19: Quantities Traded in Treatment INC 


\section{E Appendix (for Online Publication): Bids in the IPO}

As a measure for the bids submitted by an individual, we take the integral of their submitted demand schedule. The mean value of this measure increases over the four rounds with similar magnitude in both treatments. We order individuals from low to high value and plot the results for rounds 1 and 4 in Figure 20. The figure again shows evidence of learning. Higher values are observed in Round 4 than in Round 1. The results also show no discernible differences between treatments with decreasing or increasing fundamentals.

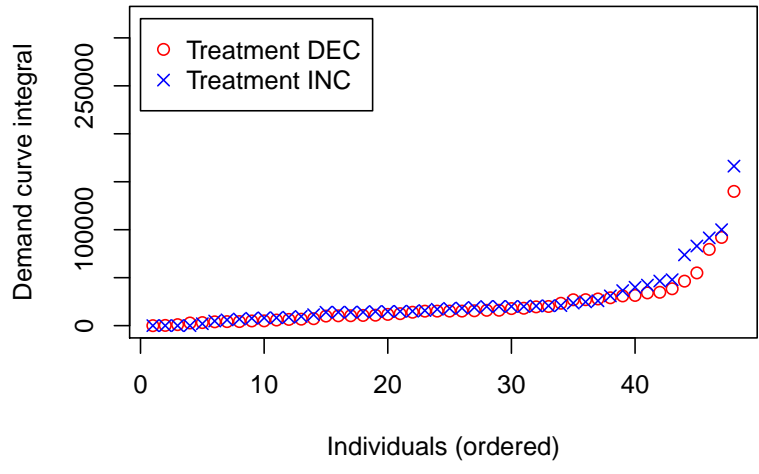

(a) Round 1

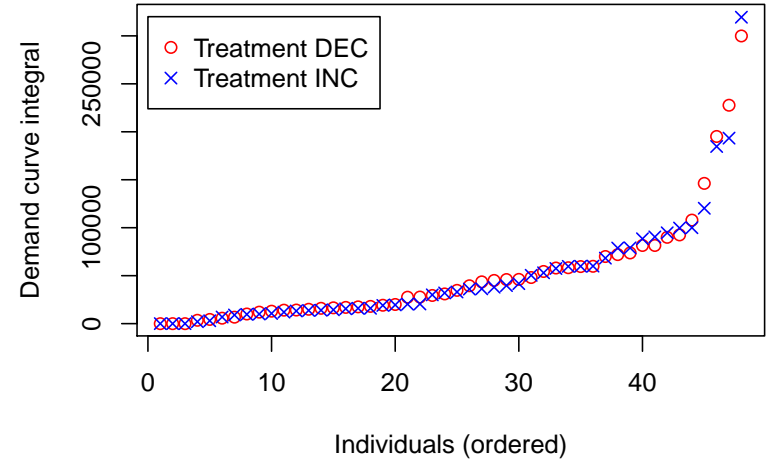

(b) Round 4

Figure 20: Integrals of Demand Curves Submitted in the IPO in the First and Last Rounds

Notes: The figures show the integrals of the submitted demand curves in the IPO by all subjects in round 1 and round 4. Subjects are ordered from lowest value to highest value.

While the aggregate price data suggests learning, the data also show evidence of irrationality for some subjects. Bidding for all 25 bonds at the equilibrium fundamental value can be seen as an upper bound on rational bids. This is because buying 25 bonds at the equilibrium price would yield no earnings while it does involve risk. This upper bound is at roughly $25 * 1860=46,500$. In all rounds there are demand schedules submitted that imply a willingness to pay up to 320,000 in the fourth round. The number of subjects submitting a demand schedule that implies a willingness to pay greater than 46,500 is increasing over the rounds (in $D E C$ the number is $4,12,18$, and 18 , in rounds $1,2,3,4$, respectively; the corresponding numbers in $I N C$ are $6,16,22$, and 18; in both treatments there are 48 subjects). It is interesting to see that such irrational bids do not result in poor market performance. Note that extremely high bids are placed at the 
beginning of the aggregate demand schedule. There are not enough of them to distort the price at which aggregate demand crosses the supply of 25. 